
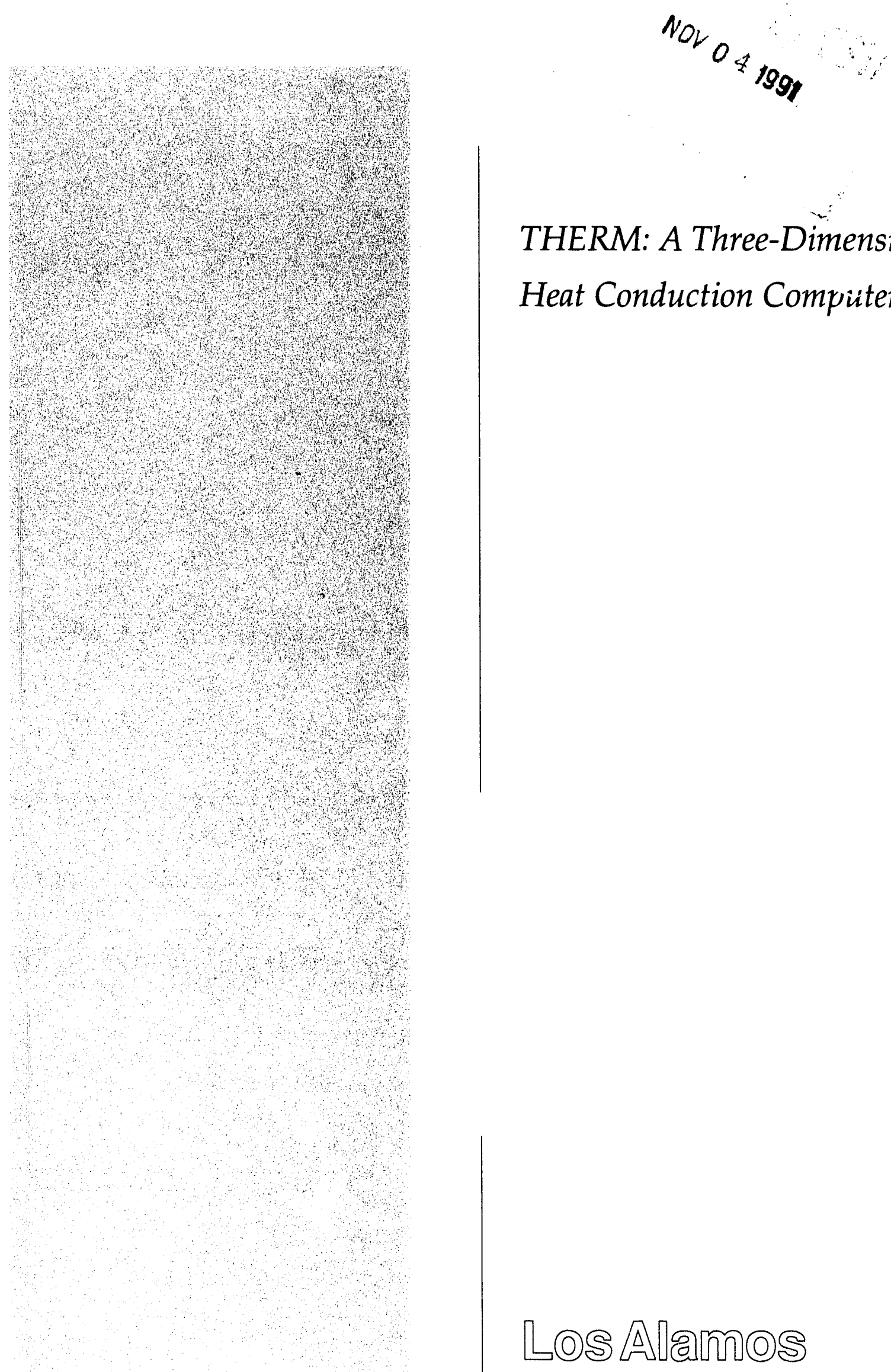

\title{
THERM: A Three-Dimensional Transient Heat Conduction Computer Program
}

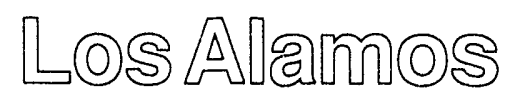

Los Alamos National Laboratory is operated by the University of California for the United States Department of Energy under contract W-7405-ENG-36. 


\section{Prepared by Juanita Lujan, Group N-6}

\section{An Affirmative Action/Equal Opportunity Employer}

This report was prepared as an account of work syonsored by an agency of the United States Government. Neither The Regents of the University of California, the United States Government nor any agency therr of, nor any of their employees, makes any warranty, express or implied, or assumes any 'egal liability or responsibility for the accurary, completeness, or usefulness of any informution, apparatus, product, or process disclosed, or represents that its use would not infringe privately owned rights. Reference herein to any specific commercial product, process, or service by trade name, trademark, manufacturer, or otherwise, does not necessarily constitute or imply its endorsement, recommendation, or favoring by The Regents of the University of California, the United States Government, or any agency thereof. The riews and opinions of authors expressed herein do not necessarily state or reflect those of The Regents of the University of California, the United States Government, or any agency thereof. 
THERM: A Three-Dimensional Transient

\section{Heat Conduction Computer Program}

W. A. Cook

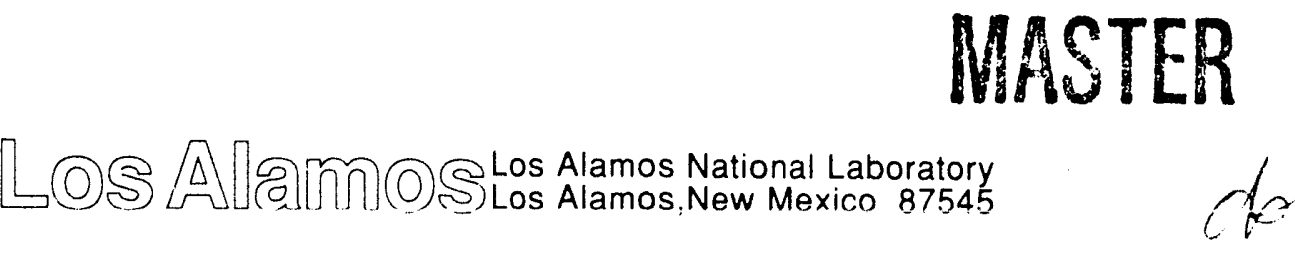




\section{CONTENTS}

\section{Page}

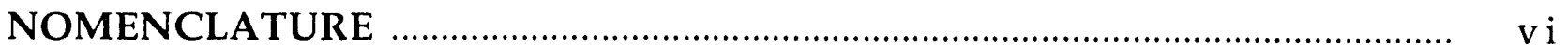

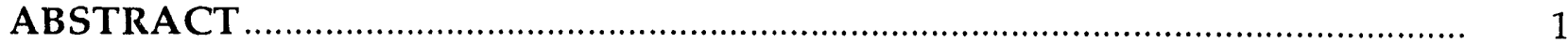

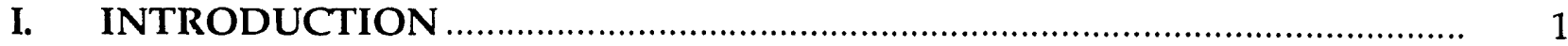

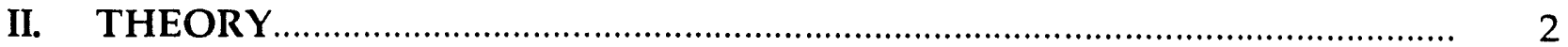

A. Vector Analysis Approach.......................................................................... 2

1. Heat Conduction Equation and Boundary Conditions....................... 2

2. Variational Principle ........................................................................ 3

3. Finite-Element Formulation ................................................................ 4

B. Tensor Analysis Approach .......................................................................... 6

1. Heat Conduction Equation and Boundary Conditions....................... 6

2. Variational Principle ............................................................................ 7

3. Finite-Element Formulation ................................................................ 8

C. Formulation of Time Integration .......................................................... 10

D. Accuracy Estimate............................................................................... 11

III. EXAMPLE PROBLEMS ………...................................................................... 11

A. Rectangular Problem .............................................................................. 11

B. Cylindrical Problems ............................................................................. 12

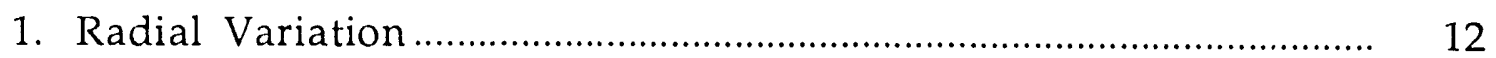

2. Circumferential Variation ............................................................... 16

C. Reactor Example Problem ………………................................................ 16

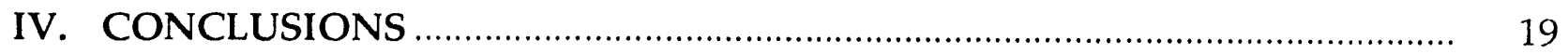

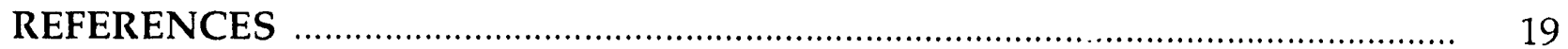

APPENDIX A: CARTESIAN COORDINATES ………………............................. 21

APPENDIX B: CYLINDRICAL COORDINATES ……………................................. 23

APPENDIX C: COVARIANT DIFFERENTIATION ………………….................... 25

APPENDIX D: THERM PROGRAM LISTING ………………................................. 27 


\section{NOMENCLATURE}

c Specific heat or heat capacity $[\mathrm{J} /(\mathrm{kg} \mathrm{K})]$.

$\mathrm{D}^{\alpha} \quad$ Element matrix defined by Eq. (21).

D Global matrix of $\mathrm{D}^{\alpha}$.

$\mathbf{e}_{\mathrm{r}}$ Unit vector in $\mathrm{r}$ direction of the cylindrical coordinate system.

$\mathbf{e}_{\varphi} \quad$ Unit vector in $\varphi$ direction of the cylindrical coordinate system.

$\mathrm{F}^{\alpha} \quad$ Element matrix defined by Eq. (20).

F Global matrix of $F^{\alpha}$.

$G^{\alpha \beta} \quad$ Element matrix defined by Eq. (19).

G Global matrix of $G^{\alpha \beta}$.

h Convective heat-transfer coefficient.

i Unit vector in $x$ direction of the Cartesian coordinate system.

j Unit vector in y direction of the Cartesian coordinate system.

$\mathrm{k} \quad$ Unit vector in $\mathrm{z}$ direction of the Cartesian coordinate system.

$\mathrm{k}_{\mathrm{x}}$ Conductivity for $\mathrm{x}$ direction $[\mathrm{W} /(\mathrm{m} \mathrm{K})]$. Similar conductivities are defined for the $y, z, r$, and $\varphi$ directions.

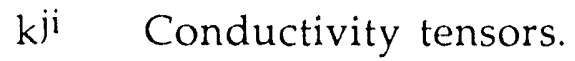

$\mathrm{kg}$ Kilograms.

K Degrees Kelvin.

J Joules.

m Meters.

n Unit normal vector.

$\mathrm{n}_{\mathrm{i}} \quad$ Component of the normal tensor.

$\mathrm{p}^{\alpha} \quad$ Finite-element shape functions.

In Normal heat flux $\left(\mathrm{W} / \mathrm{m}^{2}\right)$.

q Heat flux vector.

$\mathrm{q}^{\mathrm{i}} \quad$ Tensor component of the heat flux.

Q Internal heat source density $\left(\mathrm{W} / \mathrm{m}^{3}\right)$.

$\mathrm{r} \quad$ Radial coordinate of cylindrical coordinates.

$\mathrm{R}^{\alpha \beta \beta} \quad$ Element matrix defined by Eq. (22).

$\mathbf{R} \quad$ Global matrix of $R^{\alpha} \beta$.

s Seconds.

$S^{\alpha} \beta \quad$ Element matrix defined by Eq. (18).

$S \quad$ Global matrix of $S^{\alpha} \beta$.

$\mathrm{S} \quad$ Surface of the body $\left(\mathrm{m}^{2}\right)$. 
$\mathrm{S}_{\mathrm{q}} \quad$ Surface of the body with heat flux boundary condition $\left(\mathrm{m}^{2}\right)$.

$\mathrm{S}_{\theta} \quad$ Surface of the body with temperature boundary condition $\left(\mathrm{m}^{2}\right)$.

$\mathrm{t} \quad$ Time (s).

$\mathrm{V}$ Volume of the body $\left(\mathrm{m}^{3}\right)$.

W Watts.

$x^{i} \quad$ Curvilinear coordinates. For this report they are Cartesian coordinates $x, y, z$ or cylindrical coordinates $r, \varphi, z(m)$.

$x \quad$ Cartesian coordinate $(\mathrm{m})$.

y Cartesian coordinate $(\mathrm{m})$.

$z \quad$ Cartesian coordinate $(m)$.

$\alpha \quad$ Time integration constant that varies from 0 (explicit) to 1 (greater than 0 , implicit).

$\delta \quad$ Variational operator.

$\Delta \quad$ Designates incremental quantities.

$\theta \quad$ Temperature of the body (K).

$\theta_{\mathrm{S}} \quad$ Temperature of the surface of the body $(\mathrm{K})$.

$\theta_{\mathrm{f}} \quad$ Temperature of the flow for convective boundary $(\mathrm{K})$.

$\rho \quad$ Mass density $\left(\mathrm{kg} / \mathrm{m}^{3}\right)$.

pc Thermal capacity $\left[\mathrm{J} /\left(\mathrm{m}^{3} \mathrm{~K}\right)\right]$.

$\varphi \quad$ Circumferential coordinate of cylindrical coordinates.

$\nabla \quad$ Differential operator, defined by Eq. (1a).

$\nabla_{\mathrm{k}} \quad$ Differential operator with conductivity, defined by Eq. (1b).

; Designates covariant differentiation.

Repeated Latin indices indicate summation 1 through the number of coordinates.

Repeated Greek indices indicate summation 1 through the number of element nodal points.

Subscript i signifies inner.

Subscript o signifies outer. 


\title{
THERM: A THREE-DIMENSIONAL TRANSIENT HEAT CONDUCTION COMPUTER PROGRAM
}

by

\author{
W. A. Cook
}

\begin{abstract}
THERM is a three-dimensional finite-element computer program for solving transient heat conduction problems. This report presents the techniques used to develop THERM. The theory described consists of a governing equation, boundary conditions, and an equivalent variational principle. The matrix equations used in THERM are derived using both vector and tensor analysis. These equations used finite-element approximations for the geometry and a finite-difference approximation for the time. THERM has fir ite-element formulations using both Cartesian or cylindrical coordinates. Several example problems are included to demonstrate that the THERM formulations are correct and that THERM can be used to solve meaningful problems.
\end{abstract}

\section{INTRODUCTION}

This report presents the techniques used to develop THERM, a threedimensional computer program which solves transient heat conduction problems. This computer program uses the finite-element method to approximate geometry and the finite difference method to approximate time. THERM has continuum and boundary finite elements using both Cartesian and cylindrical coordinates. 
Both vector analysis and tensor analysis are used to present the governing equation, boundary conditions, variational principle, and to derive the finiteelement equations. Each derivation is general and can be used for any coordinate system. Appendix A presents the significant equations in Cartesian coordinates and Appendix B presents them in cylindrical coordinates. Appendix $\mathrm{C}$ presents the Christoffel symbols for Cartesian and cylindrical coordinates required for covariant differentiation in the tensor analysis approach.

The program's ability to solve thermal problems was verified with simple rectangular and cylindrical example problems, and a reactor example problem was used to check its performance. THERM is listed in Appendix D with input instructions included as comments in the listing.

Temperature is represented as $\theta$, heat flux as $\mathbf{q}$, time as $t$, heat source as $Q$, volume as $V$, surface as $S$, conductivity as $k$, and thermal capacity as $\rho c$. A complete listing of symbols is contained in the nomenclature.

\section{THEORY}

This section presents the governing equation and boundary conditions for heat conduction and the corresponding variational principle. Both vector analysis and tensor analysis are used in developing the finite-element approximations. This section concludes with the finite difference approximation of the time and an estimate of accuracy.

\section{A. Vector Analysis Approach}

This subsection uses vector analysis to derive general finite-element equations for thermal heat conduction. Appendices A and B present the significant equations of this subsection in Cartesian and cylindrical coordinates, respectively.

1. Heat Conduction Equation and Boundary Conditions. The governing equation for heat conduction is

$$
\nabla \cdot\left(\nabla_{k} \theta\right)+Q=\rho c \frac{\partial \theta}{\partial t} \text { in } V,
$$

where, for Cartesian coordinates, 


$$
\nabla \equiv \mathbf{i} \frac{\partial}{\partial x}+\mathbf{j} \frac{\partial}{\partial y}+\mathbf{k} \frac{\partial}{\partial z}
$$

or, for cylindrical coordinates,

$$
\nabla \equiv \mathbf{e}_{\mathrm{r}} \frac{\partial}{\partial \mathrm{r}}+\mathbf{e}_{\varphi} \frac{1}{\mathrm{r}} \frac{\partial}{\partial \varphi}+\mathbf{k} \frac{\partial}{\partial \mathrm{z}}
$$

and, for Cartesian coordinates,

$$
\nabla_{k} \equiv \mathbf{i k} \frac{\partial}{\partial x}+j k_{y} \frac{\partial}{\partial y}+k k_{z} \frac{\partial}{\partial z},
$$

or, for cylindrical coordinates,

$$
\nabla_{k} \equiv e_{r} k_{r} \frac{\partial}{\partial r}+e_{\varphi} \frac{k_{\varphi}}{r} \frac{\partial}{\partial \varphi}+k k_{z} \frac{\partial}{\partial z}
$$

The boundary conditions are

$$
\nabla_{\mathrm{k}} \theta=\mathbf{q} \text { on } \mathrm{S}_{\mathrm{q}}
$$

and

$$
\theta=\theta_{s} \text { on } S_{\theta} \text {. }
$$

2. Variational Principle. In this subsection the variational principle is shown to be equivalent to the governing equation and the boundary conditions.

Consider the following variational principle:

$$
\int_{V}\left[\left(\nabla_{k} \theta\right) \cdot \delta(\nabla \theta)\right] d V-\int_{V}\left(Q-\rho c \frac{\partial \theta}{\partial t}\right) \delta \theta d V-\int_{S_{q}}(\mathbf{n} \cdot \mathbf{q}) \delta \theta d S=0 .
$$

The Gauss divergence theorem is 


$$
\int_{V}(\nabla \cdot \mathbf{A}) d V=\int_{S}(\mathbf{n} \cdot \mathbf{A}) d S
$$

Let

$$
\mathbf{A}=\left(\nabla_{\mathrm{k}} \theta\right) \delta \theta
$$

then

$$
\int_{V}\left\{\nabla \cdot\left[\left(\nabla_{k} \theta\right) \delta \theta\right]\right\} d V=\int_{S}\left\{n \cdot\left[\left(\nabla_{k} \theta\right) \delta \theta\right]\right\} d S
$$

The first integral of Eq. (7) can be written as two integrals such that Eq. (7) becomes

$$
\int_{V}\left[\left(\nabla_{k} \theta\right) \cdot \delta(\nabla \theta)\right] d V=\int_{S}\left[n \cdot\left(\nabla_{k} \theta\right)\right] \delta \theta d S-\int_{V}\left[\nabla \cdot\left(\nabla_{k} \theta\right)\right] \delta \theta d V .
$$

Substituting Eq. (8) into Eq. (4) gives

$$
-\int_{V}\left\{\left[\nabla \cdot\left(\nabla_{k} \theta\right)\right]+Q-\rho c \frac{\partial \theta}{\partial t}\right\} \delta \theta d V+\int_{S}\left\{n \cdot\left[\left(\nabla_{k} \theta\right)-\mathbf{q}\right]\right\} \delta \theta d S=0 .
$$

Eq. (9) is zero in $\mathrm{V}$ if

$$
\nabla \cdot\left(\nabla_{k} \theta\right)+Q-\rho c \frac{\partial \theta}{\partial t}=0
$$

When $\theta=\theta_{\mathrm{S}}, \delta \theta=0$ on $\mathrm{S}_{\theta}$; and on $\mathrm{S}_{\mathrm{q}}$

$$
\nabla_{\mathrm{k}} \theta=\mathbf{q}
$$

3. Finite-Element Formulation. Equation (4) is the variational principle used to develop the finite-element model. The finite-element assumption is that, over each element $\mathrm{m}$, the temperature varies as follows: 


$$
\theta=p^{\alpha}\left(\xi^{i}\right) \theta_{\alpha}
$$

where repeated Greek letters are summed over all element nodal points. Thus,

$$
\nabla \theta=\left\{\nabla\left[p^{\alpha}\left(\xi^{i}\right)\right]\right\} \theta_{\alpha} \text {. }
$$

Let $\mathrm{q}$ be defined as

$$
\mathbf{n} \cdot \mathbf{q}=\mathbf{q}_{\mathbf{n}}-\mathrm{h}\left(\theta-\theta_{\mathrm{f}}\right) .
$$

Let these quantities be constant on the boundary of element $\mathrm{m}$ :

$$
\mathrm{h}=\mathrm{h}_{\mathrm{m}}, \quad \theta_{\mathrm{f}}=\left(\theta_{\mathrm{f}}\right)_{\mathrm{m}}, \quad \text { and } \quad \mathrm{q}_{\mathrm{n}}=\left(\mathrm{q}_{\mathrm{n}}\right)_{\mathrm{m}} .
$$

Let the heat source, $Q$, be a constant material quantity and thus, for element $m$,

$$
\mathrm{Q}=\mathrm{Q}_{\mathrm{m}}
$$

Let thermal capacity, $\rho c$, and conductivities, $k_{x}$ or $k_{r}, k_{y}$ or $k_{\theta}$, and $k_{z}$, be constant with respect to the geometry of element $m$ but vary with temperature.

Substituting Eqs. (12) through (16) into Eq. (4), we obtain

$$
\sum_{m}\left\{\left[\left(S^{\alpha \beta}\right)_{m}+\left(G^{\alpha \beta}\right)_{m}\right] \theta_{\beta}-\left(F^{\alpha}\right)_{m}-\left(D^{\alpha}\right)_{m}+\left[\left(R^{\alpha \beta}\right)_{m}\right]\left(\frac{\partial \theta_{\beta}}{\partial t}\right)\right\} \delta \theta_{\alpha}=0,
$$

where

$$
\begin{aligned}
& \left(s^{\alpha \beta}\right)_{m}=\int_{\left(V_{l_{n}}\right.}\left[\left(\nabla_{k} p^{\beta}\right) \cdot\left(\nabla p^{\alpha}\right)\right] d V, \\
& \left(G^{\alpha \beta}\right)_{m}=h_{m} \int_{\left(\S_{q}\right)_{n}}\left(p^{\alpha} p^{\beta}\right) d S,
\end{aligned}
$$




$$
\begin{aligned}
& \left(F^{\alpha}\right)_{m}=\left[h_{m}\left(\theta_{f} h_{m}+\left(q_{n} h_{m}\right)\right] \int_{\left(\xi_{q}\right\}_{n}}\left(p^{\alpha}\right) d S,\right. \\
& \left(D^{\alpha}\right)_{m}=Q_{m} \int_{\left(V_{m}\right.}\left(p^{\alpha}\right) d V
\end{aligned}
$$

and

$$
\left(R^{\alpha \beta}\right)_{m}=\rho c \int_{\left(V_{\mathrm{m}}\right.}\left(\mathrm{p}^{\alpha} \mathrm{p}^{\beta}\right) d V
$$

Define $\Theta$ as the global nodal point temperature matrix. Similarly define $S, G, F, D$, and $\mathbf{R}$ as the global matrices for the element matrices defined by Eqs. (18), (19), (20), (21), and (22). With these definitions, Eq. (17) can be written as

$$
(\mathbf{S}+\mathbf{G}) \Theta+\mathbf{R} \frac{\partial \Theta}{\partial t}=\mathbf{F}+\mathbf{D}
$$

\section{B. Tensor Analysis Approach}

This subsection uses tensor analysis to derive general finite-element equations for thermal heat conduction. Appendix $C$ presents the particulars for covariant differentiation in Cartesian and cylindrical coordinates. Appendices $\mathrm{A}$ and $\mathrm{B}$ present the significant equations of this subsection in Cartesian and cylindrical coordinates, respectively.

1. Heat Conduction Equation and Boundary Conditions. The governing tensor equation for heat conduction is

$$
\left(\mathrm{k}^{\mathrm{ji}} \theta_{; \mathrm{i} i \mathrm{j}}+\mathrm{Q}=\rho \mathrm{c} \frac{\partial \theta}{\partial \mathrm{t}} \text { in } \mathrm{V}\right.
$$

where ";" designates covariant differentiation with respect to $x^{i}$ (see Appendix C).

The boundary conditions are 


$$
\mathrm{k}^{\mathrm{ji}} \theta_{; \mathrm{i}}=\mathrm{q}^{\mathrm{j}} \text { on } \mathrm{S}_{\mathrm{q}}
$$

and

$$
\theta=\theta_{\mathrm{s}} \text { on } \mathrm{S}_{\theta}
$$

2. Variational Frinciple. In this subsection the variational principle is shown to be equivalent to the governing equation and the boundary conditions.

Consider the following variational principle:

$$
\int_{V}\left[\left(\mathrm{k}^{\mathrm{ji}} \theta_{; \mathrm{i}}\right) \delta\left(\theta_{; j}\right)\right] \mathrm{dV}-\int_{\mathrm{V}}\left[\left(\mathrm{Q}-\rho c \frac{\partial \theta}{\partial \mathrm{t}}\right) \delta \theta\right] \mathrm{dV}-\int_{\widehat{\delta}_{\mathrm{q}}}\left[\left(q^{\mathrm{j}} \mathrm{n}_{\mathrm{j}}\right) \delta \theta\right] \mathrm{dS}=0
$$

The Gauss divergence theorem is

$$
\int_{V}\left(f_{i j}^{j}\right) d V=\int_{S}\left(f^{j} n_{j}\right) d S
$$

Let

$$
\mathrm{f}^{\mathrm{j}}=\left(\mathrm{k}^{\mathrm{ji}} \theta_{; \mathrm{i}}\right) \delta \theta
$$

then

$$
\int_{V}\left\{\left[\left(k^{\mathrm{ji}} \theta_{; \mathrm{i}}\right) \delta \theta_{b j}\right\} \mathrm{dV}=\int_{\mathrm{S}}\left\{\left[\left(\mathrm{k}^{\mathrm{ji}} \theta_{; \mathrm{i}}\right) \delta \theta\right] n_{\mathrm{j}}\right\} \mathrm{d} S\right.
$$

The first integral of Eq. (7) can be written as two integrals such that Eq. (7) becomes

$$
\int_{V}\left[\left(k^{\mathrm{ji}} \theta_{; \mathrm{i}}\right) \delta\left(\theta_{; j}\right)\right] \mathrm{dV}=-\int_{V}\left\{\left[\left(\mathrm{k}^{\mathrm{ji}} \theta_{; \mathrm{i}}\right), \mathrm{j}\right] \delta \theta\right\} \mathrm{dV}+\int_{\mathrm{S}}\left\{\left[\left(\mathrm{k}^{\mathrm{ji}} \theta_{; \mathrm{i}}\right) \delta \theta\right] \mathrm{n}_{\mathrm{j}}\right\} \mathrm{dS} .
$$


Substituting Eq. (8) into Eq. (4) gives

$$
-\int_{V}\left\{\left[\left(k^{\mathrm{ji}} \theta_{; i}\right)_{; j}+Q-\rho c \frac{\partial \theta}{\partial t}\right] \delta \theta\right\} d V+\int_{S}\left\{\left[\left(k^{j i} \theta_{; i}-q^{j}\right) n_{j}\right] \delta \theta\right\} d S=0 .
$$

Eq. (9) is zero in $V$ if

$$
\left(k^{j i} \theta_{i i, j}+Q=\rho c \frac{\partial \theta}{\partial t}\right.
$$

When $\theta=\theta_{\mathrm{s}}, \delta \theta=0$ on $\mathrm{S}_{\theta} ;$ and on $\mathrm{S}_{\mathrm{q}}$,

$$
\mathrm{k}^{\mathrm{ji}} \theta_{; \mathrm{i}}=\mathrm{q}^{\mathrm{j}}
$$

3. Finite-Element Formulation. Equation (4) is the variational principle used to develop the finite-element model. The finite-element assumption is that, over each element $\mathrm{m}$, the temperature varies as follows:

$$
\theta=p^{\alpha}\left(\xi^{i}\right) \theta_{\alpha},
$$

where repeated Greek letters are summed over all element nodal points. Thus,

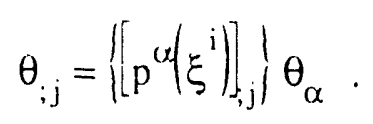

Let $\mathrm{q}$ be defined as

$$
q^{j} n_{j}=q_{n}-h\left(\theta-\theta_{f}\right) .
$$

Let these quantities be constant on the boundary of element $\mathrm{m}$ :

$$
\mathrm{h}=\mathrm{h}_{\mathrm{m}}, \quad \theta_{\mathrm{f}}=\left(\theta_{\mathrm{f}}\right)_{\mathrm{n}}, \quad \text { and } \quad \mathrm{q}_{\mathrm{n}}=\left(\mathrm{q}_{\mathrm{n}}\right)_{\mathrm{m}} .
$$

Let the heat source, $Q$, be a constant material quantity and thus, for element $m$, 


$$
\mathrm{Q}=\mathrm{Q}_{\mathrm{m}}
$$

Let thermal capacity, $\rho c$, and conductivities, $\mathrm{k}_{\mathrm{x}}$ or $\mathrm{k}_{\mathrm{r}}, \mathrm{k}_{\mathrm{y}}$ or $\mathrm{k}_{\theta}$, and $\mathrm{k}_{\mathrm{z}}$, be constant with respect to the geometry of element $m$ but vary with temperature.

Substituting Eqs. (12) through (16) into Eq. (4), we obtain

$$
\sum_{m}\left\{\left[\left(S^{\alpha \beta}\right)_{m}+\left(G^{\alpha \beta}\right)_{m}\right] \theta_{\beta}-\left(F^{\alpha}\right)_{m}-\left(D^{\alpha}\right)_{m}+\left[\left(R^{\alpha \beta}\right)_{m}\right]\left(\frac{\partial \theta_{\beta}}{\partial t}\right)\right\} \delta \theta_{\alpha}=0
$$

where

$$
\begin{aligned}
& \left(s^{\alpha \beta}\right)_{m}=\int_{\left(V_{m}\right.}\left[k^{j i}\left(p_{; i}^{\alpha}{ }_{; j}\left(p_{; j}^{\beta}\right)\right] d V,\right. \\
& \left(G^{\alpha \beta}\right)_{m}=h_{m} \int_{\left(\xi_{q}\right)}\left(p^{\alpha} p^{\beta}\right) d S \\
& \left(F^{\alpha}\right)_{m}=\left[h_{m}\left(\theta_{f}\right)_{m}+\left(q_{n}\right)\right] \int_{\left(\varsigma_{q} h_{m}\right.}\left(p^{\alpha}\right) d S, \\
& \left(D^{\alpha}\right)_{m}=Q_{m} \int_{(V)_{n}}\left(p^{\alpha}\right) d V
\end{aligned}
$$

and

$$
\left(R^{\alpha \beta}\right)_{m}=\rho c \int_{\left(V_{m}\right.}\left(p^{\alpha} p^{\beta}\right) d V
$$

Define $\Theta$ as the global nodal point temperature matrix. Similarly define S, G, F, D, and $\mathbf{R}$ as the global matrices for the element matrices defined by Eqs. (18) through (22). With these definitions Eq. (17) can be written as 


$$
(\mathbf{S}+\mathbf{G}) \Theta+\mathbf{R} \frac{\partial \Theta}{\partial t}=\mathbf{F}+\mathbf{D}
$$

\section{Formulation of Time Integration}

This section presents the finite difference operator used in this report (see Ref. 1). Define the time integration constant $\alpha$ as follows:

$$
\frac{\partial \Theta\left[x^{i}, t+\alpha(\Delta t)\right]}{\partial t}=\Delta \Theta^{j} / \Delta t
$$

and

$$
\Theta\left[x^{i}, t+\alpha(\Delta t)\right]=\Theta^{j}+\alpha\left(\Delta \Theta^{j}\right),
$$

where the superscript $j$ refers to time increment. Thus,

$$
\Theta\left(x^{i}, t+\Delta t\right)=\Theta^{j+1}=\Theta^{j}+\Delta \Theta^{j} .
$$

Substituting Eqs. (24) through (26) into Eq. (23) gives

$$
[\alpha(\mathbf{S}+\mathbf{G})+\mathbf{R} / \Delta \mathrm{t}] \Delta \Theta^{\mathrm{j}}=\mathbf{F}+\mathbf{D}-(\mathbf{S}+\mathbf{G}) \Theta^{\mathrm{j}}
$$

When $\alpha$ is 0 , the time integration is explicit (the Euler forward method); when $\alpha$ is 0.5 , the time integration is implicit (the trapezoidal rule); and when $\alpha$ is 1 , the time integration is again implicit (the Euler backward method).

Thus the time integration is a finite difference incremental approximation. The explicit time step must be small enough to maintain stability and the implicit time step small enough to preserve the accuracy of the solution (see Ref. 2). If the thermal capacity, conductivity, heat source, or convective heat-transfer coefficients vary with temperature, they could be modified with the iteration technique in THERM. The iteration technique is only meaningful with imiplicit time integration and has not been completed. 


\section{Accuracy Estimate}

The incremental iemperature nodal matrix $(\Delta \Theta)$ times the right-hand side of the master matrix equation (Eq. 27) gives an estimate of accuracy. This estimate is checked with an example: problem in Sec. III. The errors/node calculation and accuracy estimate are shown in Table III. The accuracy estimate, as a comparison number, agrees favorably with the errors/node calculation for the example problem given in Table III. In stress analysis, this type of accuracy estimate is proportional to the potential energy.

\section{EXAMPLE PROBLEMS}

This section presents several example problems that were used to test various portions of THERM. The last example is a reactor problem having special significance in reactor safety.

\section{A. Rectangular Problem}

A one-dimensional steady-state problem with rectangular geometry is described by the following governing equation:

$$
\mathrm{k} \frac{\mathrm{d}^{2} \theta}{\mathrm{dx^{2 }}}+\mathrm{Q}=0
$$

The boundary conditions are

$$
\left[k \frac{d \theta}{d x}\right]_{x=x_{0}}=q_{0}
$$

and

$$
[\theta]_{x=x_{i}}=\theta_{i}
$$

Equation (28) can be solved with the boundary conditions in Eqs. (29) and (30) to give

$$
\theta=\theta_{i}+\frac{q_{o}}{k}\left(x-x_{i}\right)+\frac{Q}{k}\left(\frac{x_{1}^{2}}{2}-x_{i} x_{o}+x x_{o}-\frac{x^{2}}{2}\right)
$$


THERM was able to solve the problem exactly, using Cartesian continuum and boundary elements and the quadratic shape functions to model the solution exactly. When $\alpha$ equals 1 and $\Delta t$ is infinite, a steady-state solution is obtained with THERM (see Table I).

\section{B. Cylindrical Problems}

1. Radial Variation. Reference 3, p. 165, presents a one-dimensional heat equation in cylindrical coordinates that allows only radial temperature variation. The boundary and general initial temperature distribution presented are for a solid cylinder. This is a one-dimensional geometry transient problem. Problem 2 in Ref. 3, p. 168, presents the temperature solution for a particular initial temperature distribution. THERM solved this problem accurately.

The governing equation is

$$
\frac{\partial \theta}{\partial t}=k\left(\frac{\partial^{2} \theta}{\partial r^{2}}+\frac{1}{r} \frac{\partial \theta}{\partial r}\right) \text {. }
$$

The boundary condition is

$$
[\theta(\mathrm{t})]_{\mathrm{T}=\mathrm{r}_{0}}=\mathrm{B}
$$

TABLE I

SOLUTION TO THE RECTANGULAR PROBLEM

\begin{tabular}{|cc||c|c|}
\hline Constants & & $\mathbf{x}(\mathrm{m})$ & $\theta(\mathrm{K})$ \\
\hline $\mathrm{q}_{\mathrm{o}}$ & $11,250 .\left(\mathrm{W} / \mathrm{m}^{2}\right)$ & 1.0 & 200. \\
$\theta_{\mathrm{i}}$ & $200 .(\mathrm{K})$ & 2.0 & $2,000$. \\
$\mathrm{k}$ & $225 .[\mathrm{W} /(\mathrm{m} \mathrm{K})]$ & 3.0 & $3,300$. \\
$\mathrm{Q}$ & $112,500\left(\mathrm{~W} / \mathrm{m}^{3}\right)$ & 4.0 & $4,100$. \\
& & 5.0 & $4,400$. \\
\hline
\end{tabular}


where $\mathrm{B}$ is a constant. The initial conditions are

$$
\begin{aligned}
& {[]_{t=\mathrm{t}_{\mathrm{o}}}=\mathrm{A}, \quad 0 \leq \mathrm{r}<\frac{\mathrm{r}}{2}} \\
& {\left[\theta_{t=\mathrm{t}_{\mathrm{o}}}=\mathrm{A}+\mathrm{B}, \quad \mathrm{r}=\frac{\mathrm{r}}{2}\right.} \\
& {\left[\theta_{t=\mathrm{t}_{\mathrm{o}}}=\mathrm{B}, \quad \frac{\mathrm{r}}{2}<\mathrm{r} \leq \mathrm{r}_{\mathrm{O}}\right.}
\end{aligned}
$$

where A and B are constants. The solution to this problem is

$$
\left.\theta(r, t)=B+\left(\frac{A-B}{2}\right) \mid \sum_{j=1}^{\infty} \frac{J_{1}\left(\lambda_{j}\right)}{\lambda_{j}\left[J_{1}\left(2 \lambda_{j}\right)\right]^{2}} J_{0}\left(\lambda_{j} r\right) e^{-k\left(\lambda_{j}\right)^{2} t}\right\} \text {, }
$$

where $\lambda_{1}, \lambda_{2} \ldots$ etc., are the positive roots of $J_{0}(2 \lambda)$.

A computer program was written to solve for 60 roots, and then using these roots, another computer program was written to calculate the series solution in Eq. (35). Due to the discontinuous temperature distribution, this was a very demanding problem but THERM solved it quite accurately with four equally spaced quadratic elements in the radial direction.

A one-dimensional steady-state problem with cylindrical geometr̃y is described by the following governing equation:

$$
\frac{k}{r} \frac{d}{d r}\left(r \frac{d \theta}{d r}\right)+Q=0 .
$$

The boundary conditions are

$$
\left[k \frac{d \theta}{d r}\right]_{r=r_{0}}=q_{0}
$$

and

$$
[\theta]_{f=r_{i}}=\theta_{i} \text {. }
$$


Equation (36) can be solved with the houndary conditions in Eqs. (37) and (38) to give

$$
\theta=\theta_{i}-\frac{Q}{4 k}\left(r^{2}-r_{i}^{2}\right)+\frac{r_{0}}{k}\left(\frac{r_{0}}{2} Q+q_{o}\right)\left[\log _{c}\left(\frac{r}{r_{i}}\right)\right]
$$

THERM's solution to Eq. (39) is given in Table II.

THERM solved this problem approximately using the linear and quadratic shape functions. The incremental temperature nodal matrix times the right-hand side of the master matrix equation, $\Delta \Theta \bullet$ (RHS), gives an estimate of accuracy. This estimate is shown in Table III to compare solutions. This error estimate is a reasonable one because it is a scalar that increases as the errors/node decreases, as shown in Table III

The $\Delta \Theta \bullet($ RHS : results are plotted in Fig. 1. The results for the 27-nodal-point elements are higher and represent more accurate calculations than the 8-nodalpoint elements, which are lower and represent less accurate calculations.

An inspection of Fig. 1 reveals that the accuracy of both the 27-nodal-point elements and the 8-nodal-point elements are nearly linear with respect to the number of radial nodal points. Even though the accuracy for a given number of nodal points is slightly less for the 8-nodal-point elements than for the 27-nodal-point elements, the finite-element calculations are considerably more expensive for 27-nodal-point elements. These types of problems lend themselves to having as few nodal points as possible to model the geometry and approximation functions as simple as possible. If the temperature variations had larger gradients, the higherorder elements would be more efficient.

\section{TABLE II}

SOLUTION TO THE CYLINDRICAL PROBLEM WITH RADIAL VARIATION

\begin{tabular}{|cc||l|l|}
\hline Constants & & $\mathbf{r}(\mathbf{m})$ & $\theta(\mathrm{K})$ \\
\hline $\mathrm{q}_{\mathrm{o}}$ & $11,250 .\left(\mathrm{W} / \mathrm{m}^{2}\right)$ & 0.04 & 2.0 \\
$\theta_{\mathrm{i}}$ & $2.0(\mathrm{~K})$ & 0.055 & 4.210278 \\
$\mathrm{k}$ & $225 .[\mathrm{W} /(\mathrm{m} \mathrm{K})]$ & 0.07 & 5.784618 \\
$\mathrm{Q}$ & $112,500\left(\mathrm{~W} / \mathrm{m}^{3}\right)$ & 0.085 & 6.950164 \\
& & 0.10 & 7.822180 \\
\hline
\end{tabular}


TABLE III

ACCURACY ESTIMATE FOR CYLINDRICAL PROBLEM

WITH RADIAL VARIATION

\begin{tabular}{|r|c|c|c|}
\hline Element & Radial nodes & $\Delta \Theta \cdot($ RHS $)$ & Errors/node \\
\hline 8-node & 3 & 4967. & 0.063575 \\
27-node & 3 & 5157. & 0.01547 \\
8-node & 5 & 5469. & 0.01328 \\
27-node & 5 & 5636. & 0.01324 \\
8-node & 7 & 5876. & 0.00507 \\
27-node & 7 & 6087. & 0.00026 \\
8-node & 25 & 9302. & 0.00017 \\
27-node & 25 & 10060. & 0.0000006 \\
\hline
\end{tabular}

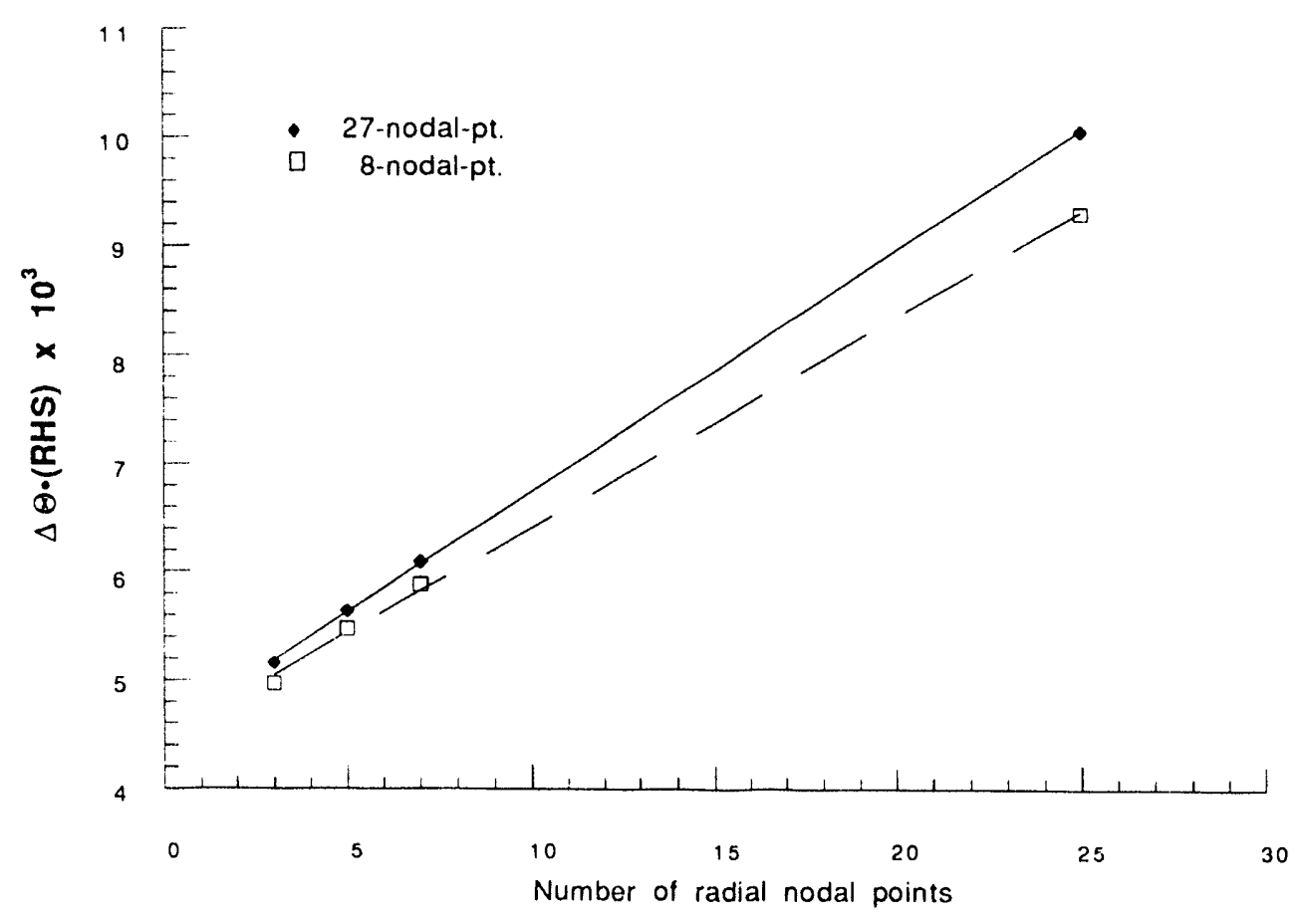

Fig. 1.

Accuracy results for cylindrical problem with radial variation. 
2. Circumferential Variation. The circumferential variation was checked by analyzing the rectangular problem in Sec. III.A with quadratic finite elements using cylindrical coordinates. The circumferential coordinate approximates the $x$ variation of the problem. The approximation functions of the quadratic finite elements using cylindrical coordinates do not solve this problem exactly but approximate very closely the correct solution.

\section{Reactor Example Problem}

A typical reactor problem is shown in Fig. 2. The details for this problem were supplied by Ref. 4 . The input parameters used for this problem are shown in Tables IV and V. Note that $\mathrm{c}$ and $\rho$ were not needed for the steady-state solution.

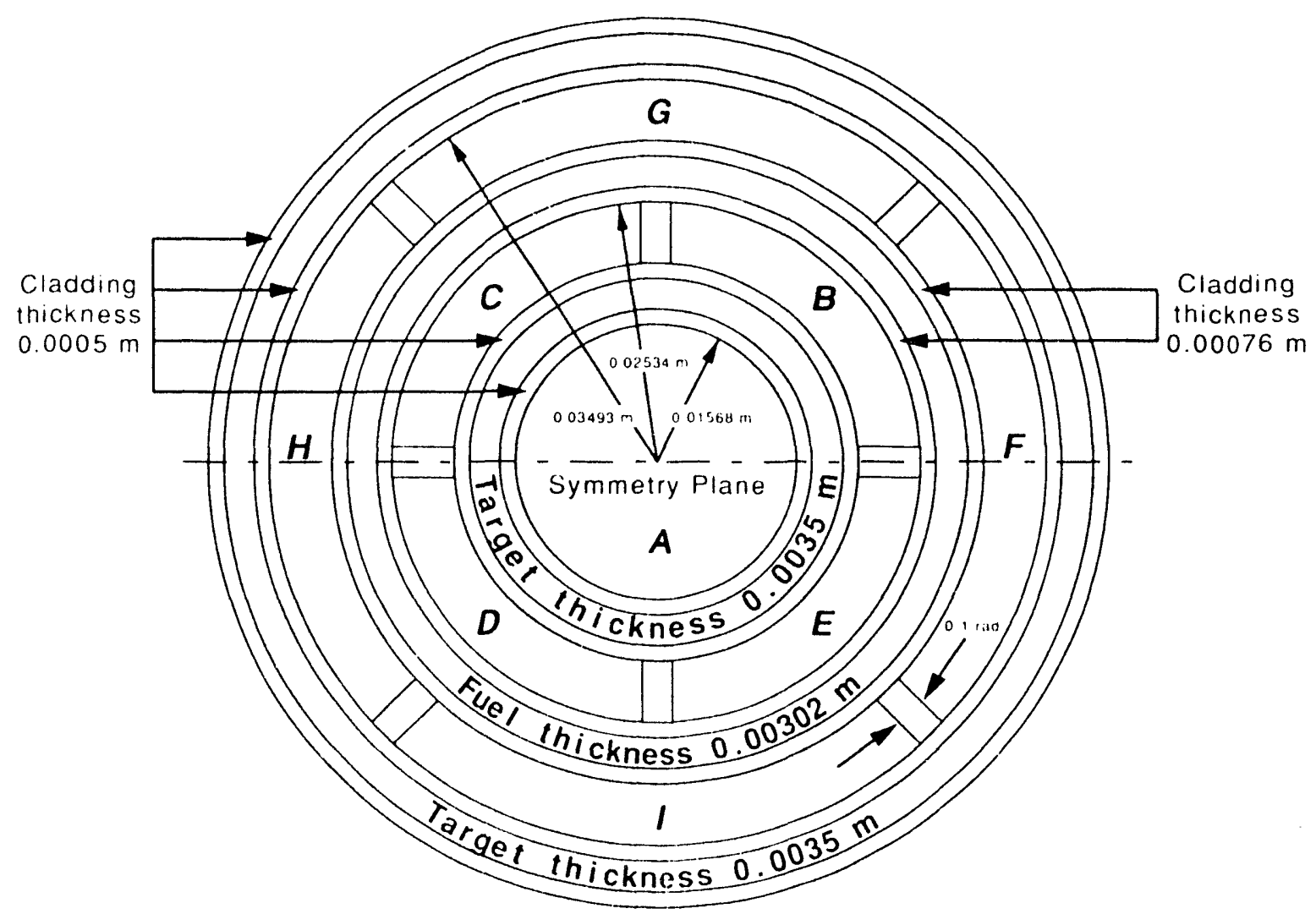

Fig. 2.

Typical reactor problem. 
TABLE IV

MATERIAL AND INTERNAL HEAT GENERATION PROPERTIES

FOR A TYPICAL REACTOR PROBLEM

\begin{tabular}{|l|c|c|c|c|}
\hline Material & $\mathbf{k}[\mathbf{W} /(\mathrm{m} \mathrm{K})]$ & $\mathrm{c}[\mathrm{j} /(\mathrm{kg} \mathrm{K})]$ & $\left.\rho \mathbf{( k g} / \mathbf{m}^{3}\right)$ & $\mathbf{Q}\left(\mathbf{W} / \mathbf{m}^{3}\right)$ \\
\hline Cladding & 240.0 & 900.0 & 2699.0 & 0.0 \\
Target & 70.96 & 3308.0 & 530.0 & 0.0 \\
Fuel & 178.27 & 845.73 & 2979.4 & $1,909,000,000$. \\
\hline
\end{tabular}

TABLE V

THERMAL BOUNDARY CONDITIONS FOR A TYPICAL REACTOR PROBLEM

\begin{tabular}{|c|c|c|}
\hline Channels & $\mathbf{T}_{\mathbf{f}}(\mathrm{K})$ & $\mathbf{h}\left[\mathbf{W} /\left(\mathbf{m}^{\mathbf{2}} \mathbf{K}\right)\right]$ \\
\hline A-E, G-I & 300.0 & $30,000.0$ \\
F & 300.0 & 0.0 \\
Exterior & 300.0 & 100.0 \\
\hline
\end{tabular}

The maximum temperature calculated for the core is plotted in Fig. 3 as a function of the circumferential angle. This calculation used 1410 nodal points and 98 27-nodal-point continuum elements.

Figure 4 is a composite of two plots of a coarse mesh consisting of 906 nodal points. One plot shows the calculation using 62 27-nodal-point continuum elements and the other plot shows the calculation using 496 8-nodal-point continuum elements.

The 8-nodal-point calculation in Fig. 4 required only $3 / 5$ the computer time required for the 27-nodal-point calculation. This type of problem should have as few nodal points as possible to model the geometry and approximation functions as simply as possible. If the temperature variation had larger gradients, the more complicated elements would be more efficient, as shown in Ref. 5 for stress analysis problems.

The $\Delta \Theta \bullet$ (RHS) values for the calculations plotted in Figs. 3 and 4 are shown in Table VI. 


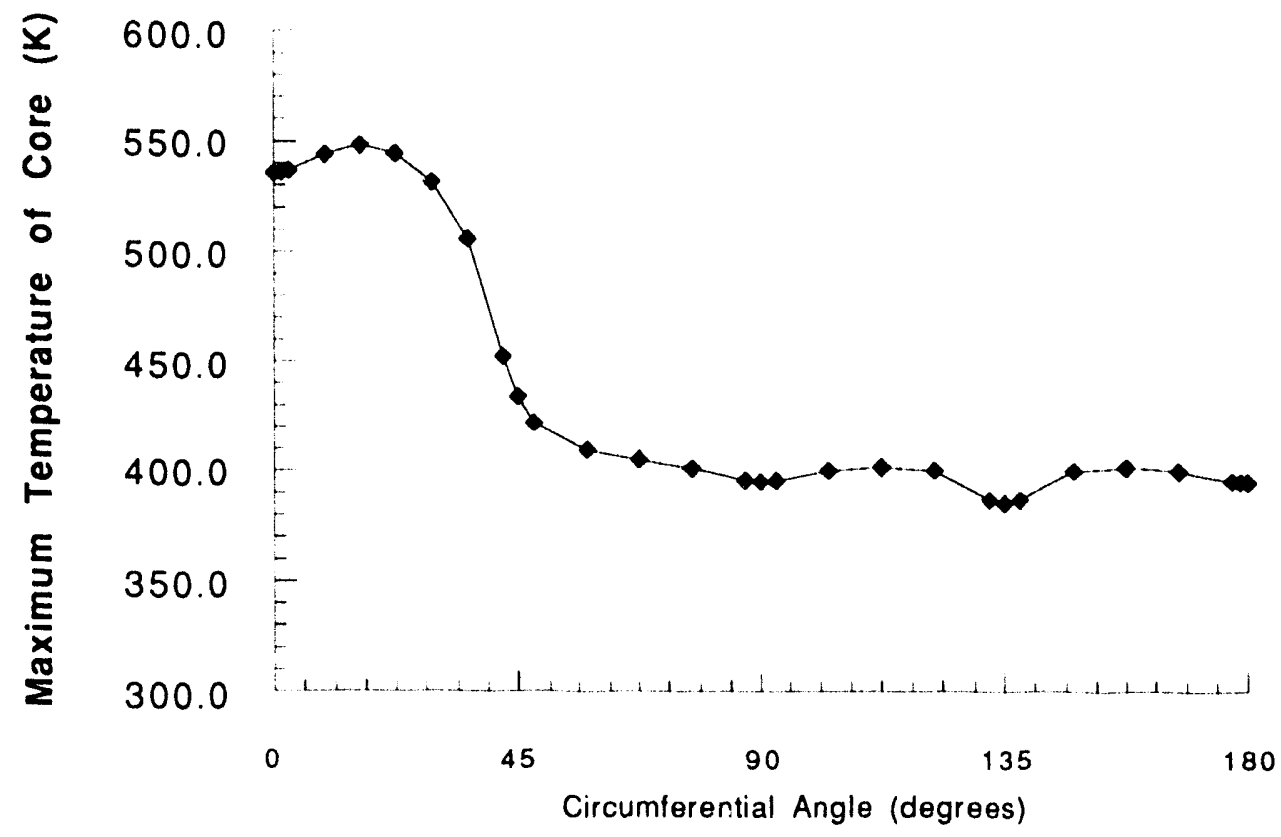

Fig. 3.

Calculation of maximum core temperature for a typical reactor problem.

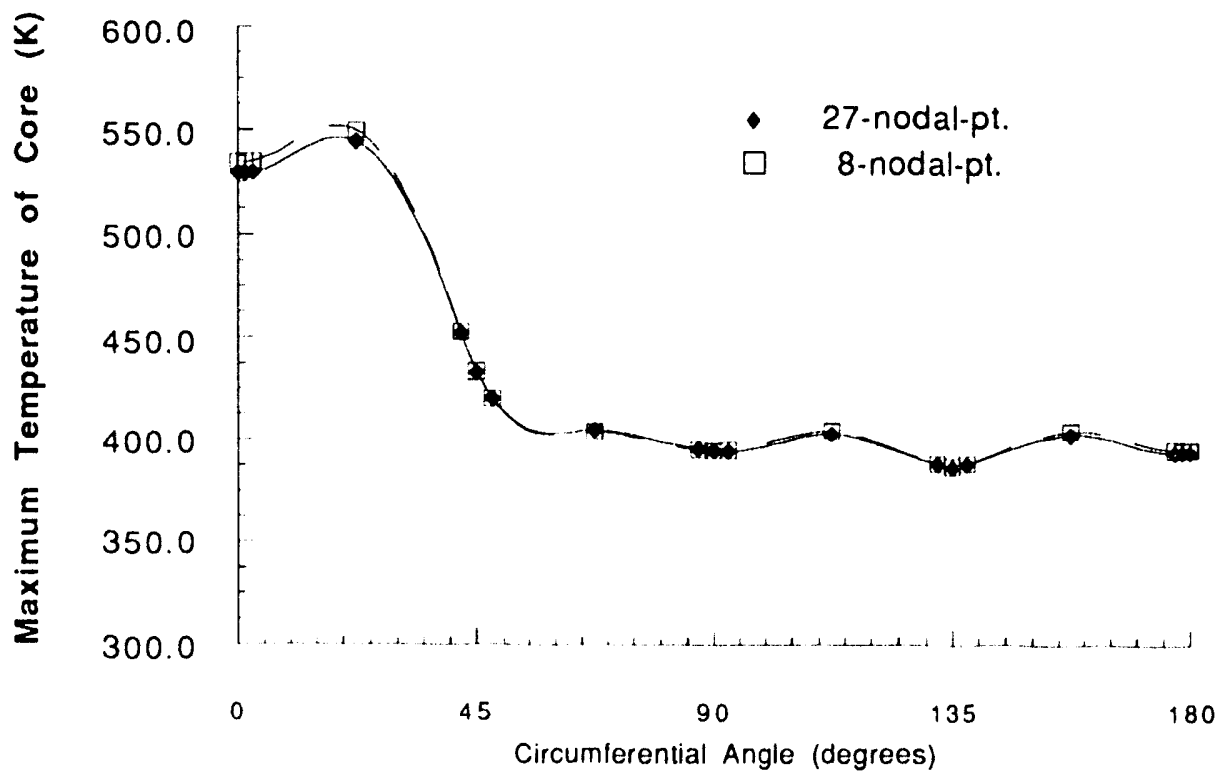

Fig. 4.

Comparison of 27- and 8-nodal-point calculations for a typical reactor problem. 
TABLE VI

ACCURACY ESTIMATE FOR A TYPICAL

REACTOR PROBLEM

\begin{tabular}{|c|c|c|}
\hline Nodal Points & Elemenis & $\Delta \Theta \cdot($ RHS) \\
\hline 906 & 8-node (cyl.) & 6572980. \\
906 & 27-node (cyl.) & 6729590. \\
1401 & 27-node (cart.) & 6776610. \\
1401 & 27-node (cyl.) & 6777010. \\
\hline
\end{tabular}

\section{CONCLUSIONS}

THERM is a three-dimensional finite-element transient heat conduction computer program. THERM solves very complicated geometry problems with extreme temperature variations. The very nature of the finite-element method and the method of integrating the finite elements requires significant computer time. For reactor problems, as shown in Sec. III.C, the computer time requirements are large compared to other methods. The computer time requirements for THERM could be reduced with single-point integration (see Ref. 6), improved matrixequation solution algorithms, and restrictions to explicit time integrations. With these improvements it is doubtful that THERM would be any better than the HERA computer program that solves these reactor problems very accurately and efficiently (Ref. 7). The types of problems solved so far with THERM lend themselves to having as few nodal points as possible to model the geometry and approximation functions that are as simple as possible. If the temperature variations had larger gradients, the higher-order elements would be more efficient.

\section{REFERENCES}

1. K. J. Bathe, "ADINAT-A Finite-Element Program for Automatic Dynamic Incremental Nonlinear Analysis of Temperatures," M.I.T Report 82448-5 (May 1977, Revised Dec. 1978).

2. R. D. Richtmyer and K. W. Morton, Difference Methods for Initial-Value Problems, 2nd Ed. (Interscience Pub. of J. Wiley \& Sons, 1967). 
3. R. V. Churchill, Fourier Series and Boundary Problems (McGraw-Hill Book Co., 1941).

4. N. M. Schnurr, Los Alamos National Laboratory, personal communication, July 1990.

5. W. A. Cook, "Body-Oriented Coordinates Applied to the Finite-Element Method," Engincering Analysis 5, 2-11 (1988).

6. T. Belytschko and W. E. Bachrach, "Efficient Implementation of Quadrilaterals with High Coarse Mesh Accuracy," Comput. Meths. Appl. Mech. Engrg. 42, 279-301 (1984).

7. W. J. Rider, M. W. Cappiello, and D. R. Liles, "A Vectorized Heat-Transfer Model for Solid Reactor Cores," in the 6th Proc. of Nuclear Thermo-Hydraulics, W. A. Hassan, editor, America Nuclear Society (1990), pp. 370-380. 


\section{APPENDIX A \\ CARTESIAN COORDINATES}

The governing equation for heat conduction, Eq. (1) of Sec. II, is

$$
\frac{\partial}{\partial x}\left(k_{x} \frac{\partial \theta}{\partial x}\right)+\frac{\partial}{\partial y}\left(k_{y} \frac{\partial \theta}{\partial y}\right)+\frac{\partial}{\partial z}\left(k_{z} \frac{\partial \theta}{\partial z}\right)+Q=\rho c \frac{\partial \theta}{\partial t} \text { in } V .
$$

The boundary conditions, Eqs. (2) and (3) of Sec. II, are

$$
k_{x} \frac{\partial \theta}{\partial x} \mathbf{i}+k_{y} \frac{\partial \theta}{\partial y} \mathbf{j}+k_{z} \frac{\partial \theta}{\partial z} \mathbf{k}=\mathbf{q} \text { on } S_{q}
$$

and

$$
\theta=\theta_{\mathrm{s}} \text { on } \mathrm{S}_{\theta}
$$

The variational principle, Eq. (4) of Sec. II, is

$$
\begin{gathered}
\int_{V}\left[k_{x} \frac{\partial \theta}{\partial x} \delta\left(\frac{\partial \theta}{\partial x}\right)+k_{y} \frac{\partial \theta}{\partial y} \delta\left(\frac{\partial \theta}{\partial y}\right)+k_{z} \frac{\partial \theta}{\partial z} \delta\left(\frac{\partial \theta}{\partial z}\right)\right] d V \\
-\int_{V}\left(Q-\rho c \frac{\partial \theta}{\partial t}\right) \delta \theta d V-\int_{\widehat{V}_{4}}(\mathbf{n} \cdot \mathbf{q}) \delta \theta d S=0 .
\end{gathered}
$$

Eqs. (13) of Sec. II are

$$
\frac{\partial \theta}{\partial x}=\left\{\frac{\partial}{\partial x}\left[p^{\alpha}\left(\xi^{i}\right)\right]\right\} \theta_{\alpha}, \frac{\partial \theta}{\partial y}=\left\{\frac{\partial}{\partial y}\left[p^{\alpha}\left(\xi^{i}\right)\right]\right\} \theta_{\alpha} \text {, and } \frac{\partial \theta}{\partial z}=\left\{\frac{\partial}{\partial z}\left[p^{\alpha}\left(\xi^{i}\right)\right]\right\} \theta_{\alpha} .
$$

Eq. (18) of Sec. II is 


$$
\left(S^{\alpha \beta}\right)_{m}=\int_{\left(V_{\mathrm{t}_{n}}\right.}\left(k_{x} \frac{\partial p^{\alpha}}{\partial x} \frac{\partial p^{\beta}}{\partial x}+k_{y} \frac{\partial p^{\alpha}}{\partial y} \frac{\partial p^{\beta}}{\partial y}+k_{z} \frac{\partial p^{\alpha}}{\partial z} \frac{\partial p^{\beta}}{\partial z}\right) d V
$$




\section{APPENDIX B}

\section{CYLINDRICAL COORDINATES}

The governing equation for heat conduction, Eq. (1) of Sec. II, is

$$
\frac{\partial}{\partial r}\left(k_{r} \frac{\partial \theta}{\partial r}\right)+\frac{k_{r}}{r} \frac{\partial \theta}{\partial r}+\frac{1}{r^{2}} \frac{\partial}{\partial \varphi}\left(k_{\varphi} \frac{\partial \theta}{\partial \varphi}\right)+\frac{\partial}{\partial z}\left(k_{z} \frac{\partial \theta}{\partial z}\right)+Q=\rho c \frac{\partial \theta}{\partial t} \text { in } V
$$

or

$$
\frac{1}{\mathrm{r}} \frac{\partial}{\partial \mathrm{r}}\left(\mathrm{k}_{\mathrm{r}} \mathrm{r} \frac{\partial \theta}{\partial \mathrm{r}}\right)+\frac{1}{\mathrm{r}^{2}} \frac{\partial}{\partial \varphi}\left(\mathrm{k}_{\varphi} \frac{\partial \theta}{\partial \varphi}\right)+\frac{\partial}{\partial z}\left(\mathrm{k}_{\mathrm{z}} \frac{\partial \theta}{\partial z}\right)+\mathrm{Q}=\rho \mathrm{c} \frac{\partial \theta}{\partial \mathrm{t}} \text { in } \mathrm{V}
$$

The boundary conditions, Eqs. (2) and (3) of Sec. II, are

$$
\mathrm{k}_{\mathrm{r}} \frac{\partial \theta}{\partial \mathrm{r}} \mathbf{e}_{\mathrm{r}}+\frac{\mathrm{k}_{\varphi}}{\mathrm{r}} \frac{\partial \theta}{\partial \varphi} \mathbf{e}_{\varphi}+\mathrm{k}_{\mathrm{z}} \frac{\partial \theta}{\partial \mathrm{z}} \mathbf{k}=\mathbf{q} \text { on } \mathrm{S}_{\mathrm{q}}
$$

and

$$
\theta=\theta_{\mathrm{s}} \text { on } \mathrm{S}_{\theta}
$$

The variational principle, Eq. (4) of Sec. II, is

$$
\begin{gathered}
\int_{V}\left[k_{r} \frac{\partial \theta}{\partial r} \delta\left(\frac{\partial \theta}{\partial r}\right)+\frac{k_{\varphi}}{r^{2}} \frac{\partial \theta}{\partial \varphi} \delta\left(\frac{\partial \theta}{\partial \varphi}\right)+k_{z} \frac{\partial \theta}{\partial z} \delta\left(\frac{\partial \theta}{\partial z}\right)\right] d V \\
-\int_{V}\left(Q-\rho c \frac{\partial \theta}{\partial t}\right) \delta \theta d V-\int_{\mathcal{q}_{1}}(\mathbf{n} \cdot \mathbf{q}) \delta \theta d S=0 .
\end{gathered}
$$

Eqs. (13) of Sec. II are

$$
\left.\frac{\partial \theta}{\partial \mathrm{r}}=\left\{\frac{\partial}{\partial \mathrm{r}}\left[\mathrm{p} \alpha\left(\xi^{\mathrm{i}}\right)\right]\right\} \theta_{\alpha}, \frac{\partial \theta}{\partial \varphi}=\left\{\frac{\partial}{\partial \varphi}\left[\mathrm{p}^{\alpha}\left\{\xi^{\mathrm{i}}\right)\right]\right\} \theta_{\alpha} \text {, and } \frac{\partial \theta}{\partial z}=\left\{\frac{\partial}{\partial \mathrm{z}}\left[\mathrm{p} \alpha \xi_{\xi^{i}}\right)\right]\right\} \theta_{\alpha} \text {. }
$$


Eq. (18) of Sec. II is

$$
\left(s^{\alpha \beta}\right)_{m}=\int_{\left(v_{m}\right.}\left(k_{r} \frac{\partial p^{\alpha}}{\partial r} \frac{\partial p^{\beta}}{\partial r}+\frac{k_{\varphi}}{r^{2}} \frac{\partial p^{\alpha}}{\partial \varphi} \frac{\partial p^{\beta}}{\partial \varphi}+k_{z} \frac{\partial p^{\alpha}}{\partial z} \frac{\partial p^{\beta}}{\partial z}\right) d V
$$




\section{APPENDIX C \\ COVARIANT DIFFERENTIATION}

Covariant differentiation of a scalar like the temperature, $\theta$, is

$$
\theta_{; i}=\frac{\partial \theta}{\partial x^{i}}
$$

Covariant differentiation of a contravariant first order tensor like $\left(\mathrm{k}^{\mathrm{ji}} \theta_{; \mathrm{i}}\right)_{; \mathrm{k}}$ is

$$
\left(\mathrm{k}^{\mathrm{ji}} \theta_{: \mathrm{i}}\right)_{; \mathrm{k}}=\frac{\partial\left(\mathrm{k}^{\mathrm{ji}} \theta_{; \mathrm{i}}\right)}{\partial \mathrm{x}^{\mathrm{k}}}+\left\{\begin{array}{c}
\mathrm{j} \\
\mathrm{ks}
\end{array}\right\}\left(\mathrm{k}^{\mathrm{si}} \theta_{; \mathrm{i}}\right) .
$$

$\left\{\begin{array}{c}\mathrm{j} \\ \mathrm{ks}\end{array}\right\}$ are Christoffel symbols of the second kind.

For Cartesian coordinates all Christoffel symbols of the second kind are zero.

For cylindrical coordinates the only nonzero Christoffel symbols of the second kind are

$$
\left\{\begin{array}{c}
1 \\
22
\end{array}\right\}=-\mathrm{r},\left\{\begin{array}{c}
2 \\
21
\end{array}\right\}=\frac{1}{\mathrm{r}} \text {, and }\left\{\begin{array}{c}
2 \\
12
\end{array}\right\}=\frac{1}{\mathrm{r}} \text {. }
$$

The conductivity tensors for Cartesian coordinates, in terms of physical conductivities, are

$$
k^{j i}=\left[\begin{array}{ccc}
k_{x} & 0 & 0 \\
0 & k_{y} & 0 \\
0 & 0 & k_{z}
\end{array}\right]
$$

The conductivity tensors for cylindrical coordinates, in terms of physical conductivities, are 


$$
\mathrm{k}^{\mathrm{ji}}=\left[\begin{array}{ccc}
\mathrm{k}_{\mathrm{r}} & 0 & 0 \\
0 & \frac{\mathrm{k}_{\varphi}}{\mathrm{r}^{2}} & 0 \\
0 & 0 & \mathrm{k}_{\mathrm{z}}
\end{array}\right] .
$$

The heat flux tensors and normal tensors for Cartesian coordinates, in terms of physical heat fluxes and physical normal vector components, are

$$
q^{i}=\left\{\begin{array}{l}
q_{x} \\
q_{y} \\
q_{z}
\end{array}\right\} \quad \text { and } \quad n_{1}=\left\{\begin{array}{c}
n_{x} \\
n_{y} \\
n_{z}
\end{array}\right\} \text {. }
$$

The heat flux and normal tensors for cylindrical coordinates, in terms of physical heat fluxes and physical normal vector components, are

$$
q^{i}=\left\{\begin{array}{c}
q_{r} \\
q_{\varphi} \\
r \\
q_{z}
\end{array}\right\} \text { and } n_{i}=\left|\begin{array}{c}
n_{r} \\
r_{\varphi} \\
n_{z}
\end{array}\right| \text {. }
$$




\section{APPENDIX D \\ THERM PROGRAM LISTING}

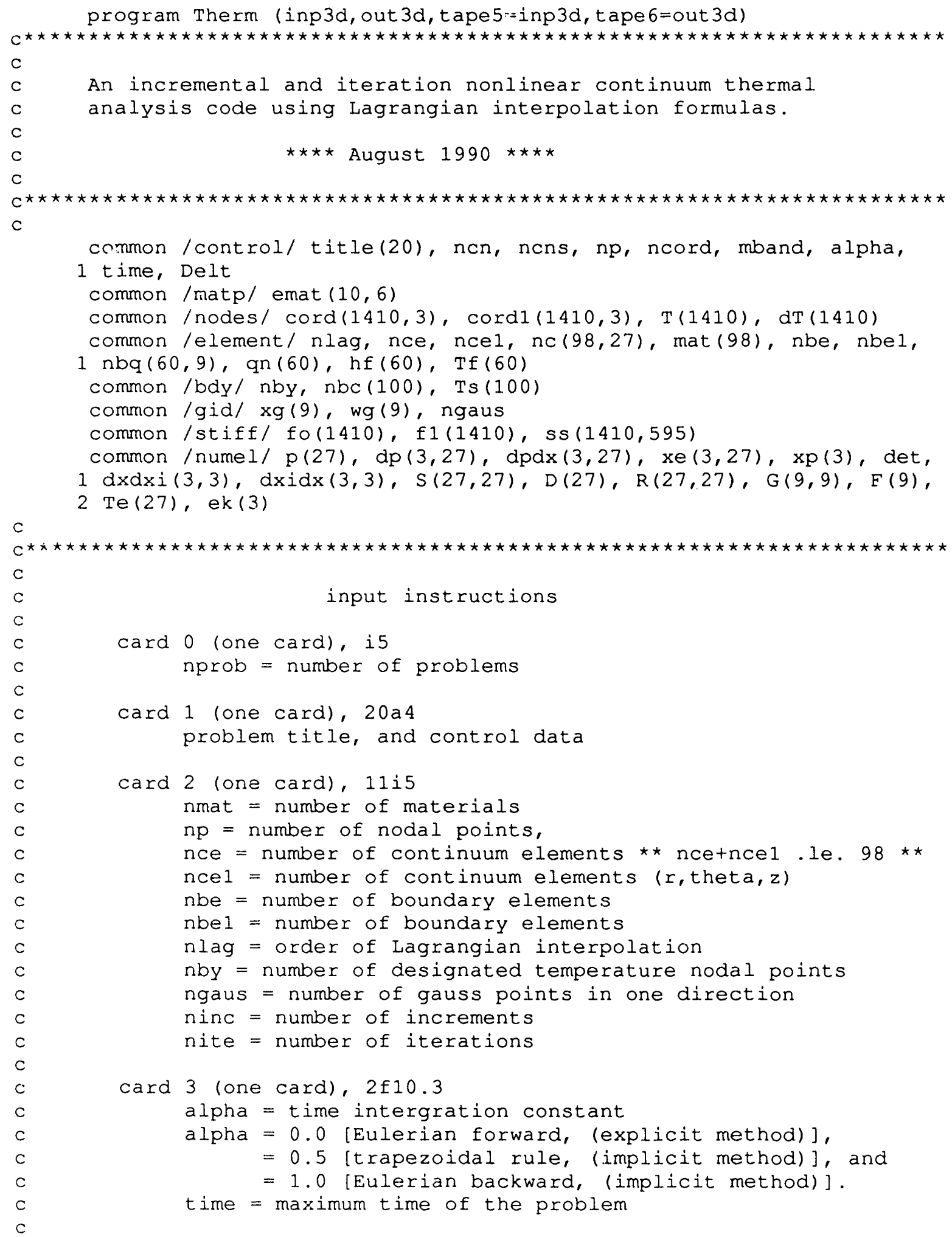




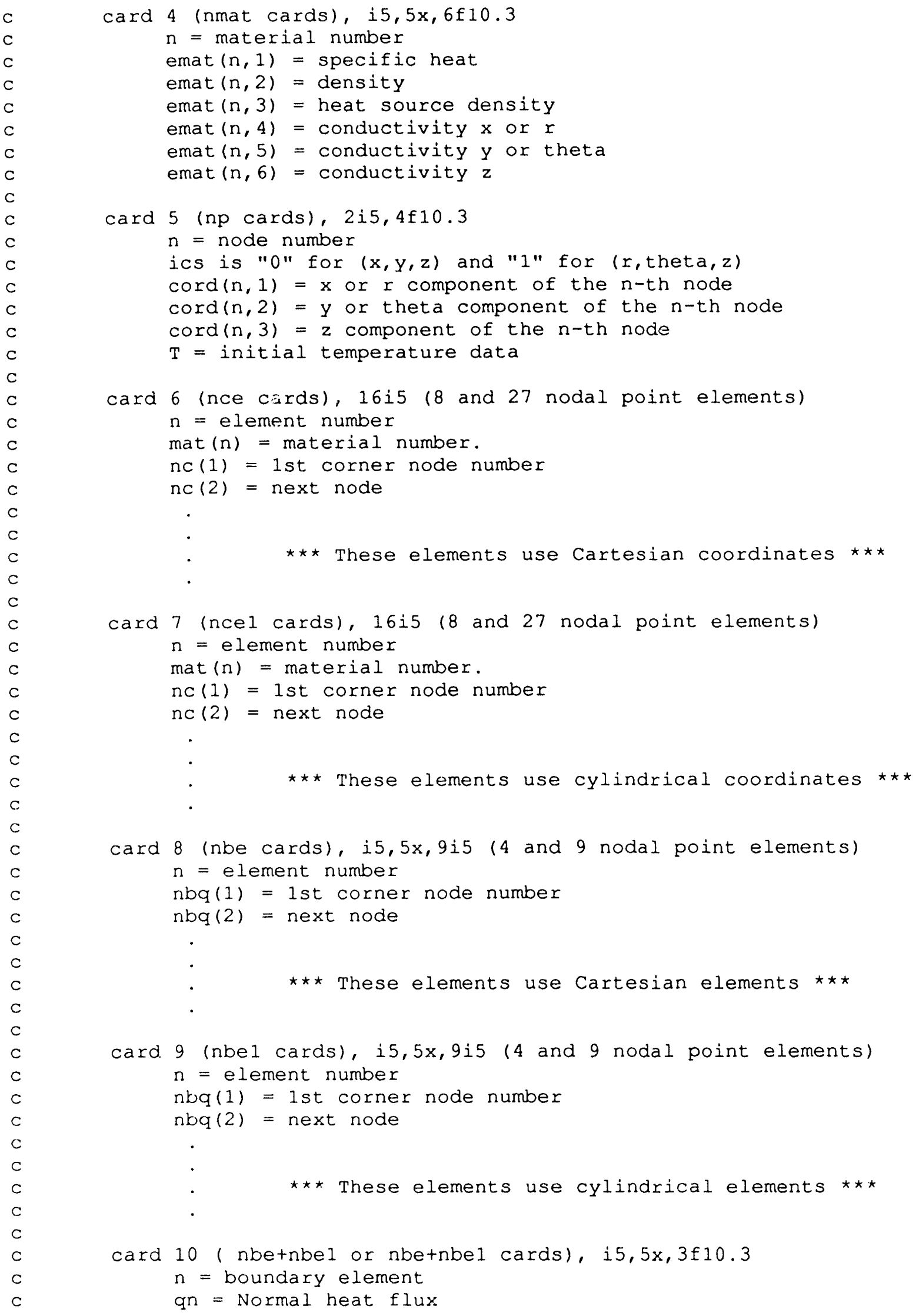




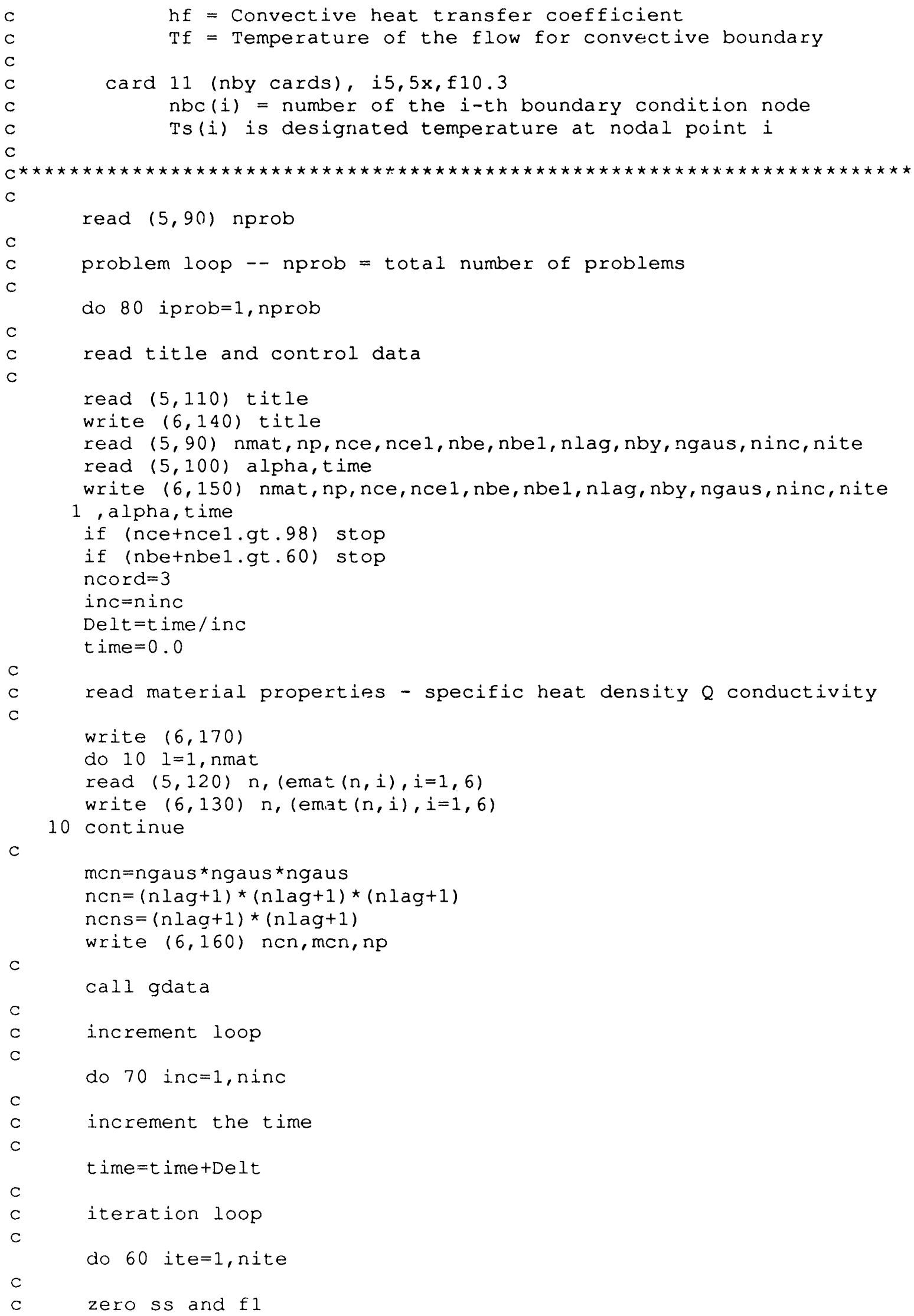


c

do $30 n=1, n p$

$\mathrm{f} 1(\mathrm{n})=0.0$

do $20 j=1$, mband

$\operatorname{ss}(n, j)=0.0$

20 continue

30 continue

c

if (nbe.ne.0) call Belemt

if (nbel.ne.0) call Belemt 1

if (nce.ne.0) call Celemt

if (ncel.ne.0) call celemt 1

C

C

C

save RHS in fo

do $40 n=1, n p$

fo $(n)=f I(n)$

40 continue

C

call solve

C

write $(6,180)$ inc, ite, time, Delt

write $(6,200)$

do $50 n=1, n p$

$T(n)=T(n)+d T(n)$

50 write $(6,190) n, T(n), \operatorname{dT}(n)$

C

call check

C

60 continue

C

70 continue

$\star \star$ ends iteration loop *

C

80 continue

$\star \star$ ends increment loop $\star \star$

c

c

stop

C

90 format (11i5)

100 format $(2 \mathrm{f} 10.3)$

110 format (20a4)

120 format $(i 5,5 x, 6 \pm 10.3)$

130 format (i5, 5x, 1p6e12.5)

140 format (1h1,5x,7htherm -,2x,20a4)

150 format ( $1 \mathrm{~h} 0,30 \mathrm{x}, 18 \mathrm{hcontrol}$ parameters/

$110 x, 30 h n u m b e r$ of materials---.----, i3//

$210 x, 30 h n u m b e r$ of nodal points-------, i5//

$310 x, 30$ hnumber of continuum elements--, i3*

$410 x, 30$ hnumber of continuum elements--, i3*

$510 x, 30$ hnumber of boundary elements--., i3*

$610 x, 30$ hnumber of boundary elements---, i3*

$710 x, 30$ horder of Lag. interpolation---, i3//

$(x, y, z) \star / /$

$(r$, thet $a, z) \star / /$

$(\mathrm{x}, \mathrm{y}, \mathrm{z}) \star / /$

$(r$, thet $a, z) \star / /$

$810 x, 30$ hnumber of displacement b.c.---,i3//

$910 x, 30$ hnumber of gauss points--.---., i3//

* $10 \mathrm{x}, 30 \mathrm{hnumber}$ of increments-...-..., i3//

$110 x, 30$ hnumber of iterations-------- i3//

$210 x, 30 h a l p h a$ (time int. constant)----, f5.2/

$310 x, \star a l p h a=0.0$ (Eulerian forward)* $/ 18 x^{\star} 0.5$ (trapezoidal rule)* 
$4 / 18 x \star 1.0$ (Eulerian backward) *//

$510 x, 30 h t i m e$ (maximum) of problem----, 1pe13.5)

160 format (1h0,14hnodes/element $=, i 2,2 \mathrm{x}, 17 \mathrm{~h}$ gaussian points=, i3, $2 \mathrm{x}, 15 \mathrm{~h}$ 1 total unknowns=, i4)

170 format $\left(1 \mathrm{~h} 0,20 \mathrm{~h}\right.$ material properties $/ 3 x^{\star}$ mat $1 \star 6 x^{\star}$ sp. heat ${ }^{\star} 5 x^{\star}$ density

$1 \star 5 x^{\star} Q^{\star} 7 x^{\star}$ conductivity $k x$ or $k r, k y$ or ktheta, $k z \star$ )

180 format ( 1 ho, $1 x^{\star}$ increment, iterate $* 2$ i $3,5 x^{\star}$ time and dt*1p2e13.5)

190 format (i10,3x,1p2e13.5)

200 format (1h0,7x*node $3 x^{\star}$ temperature $\left.{ }^{\star}\right)$

end 


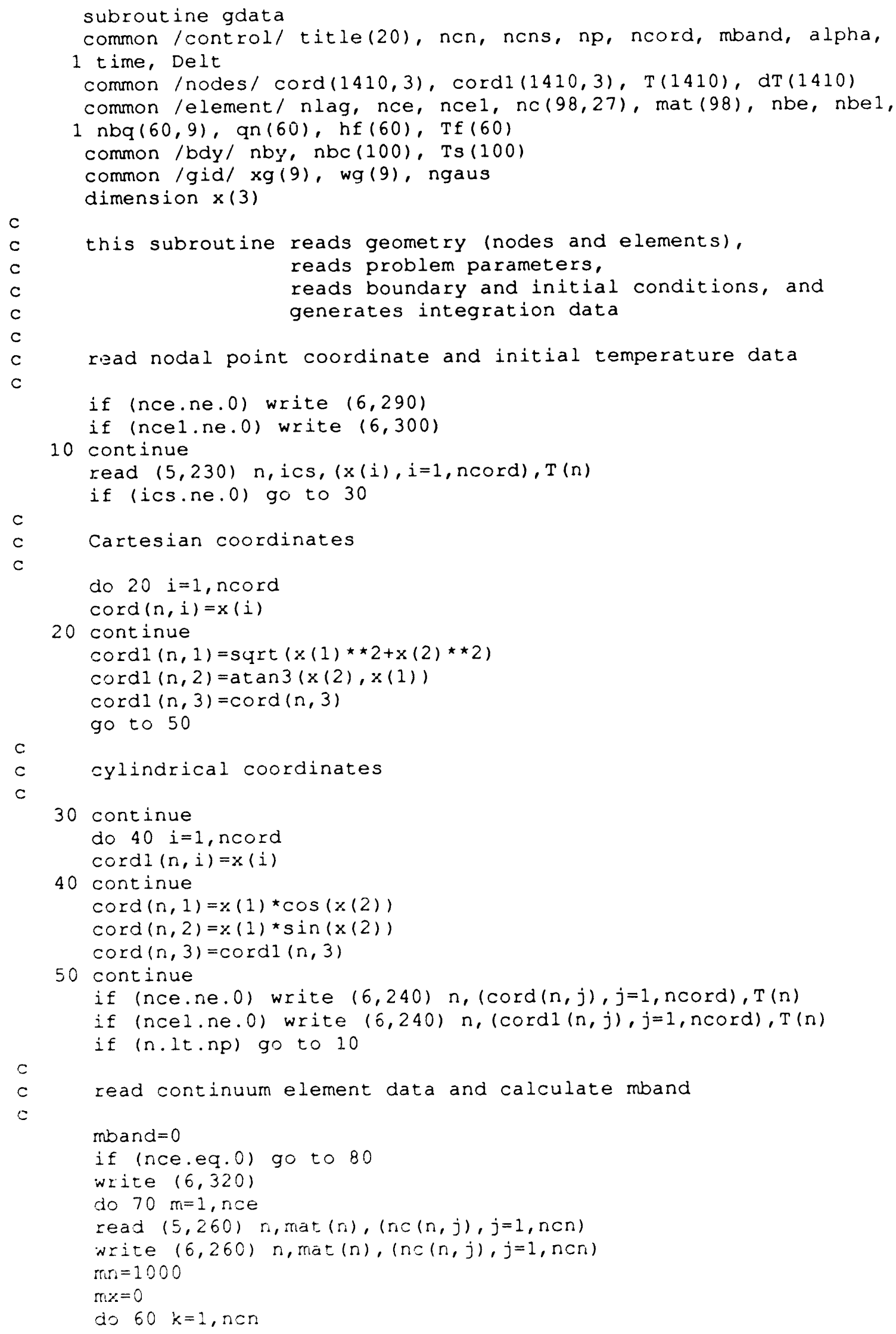




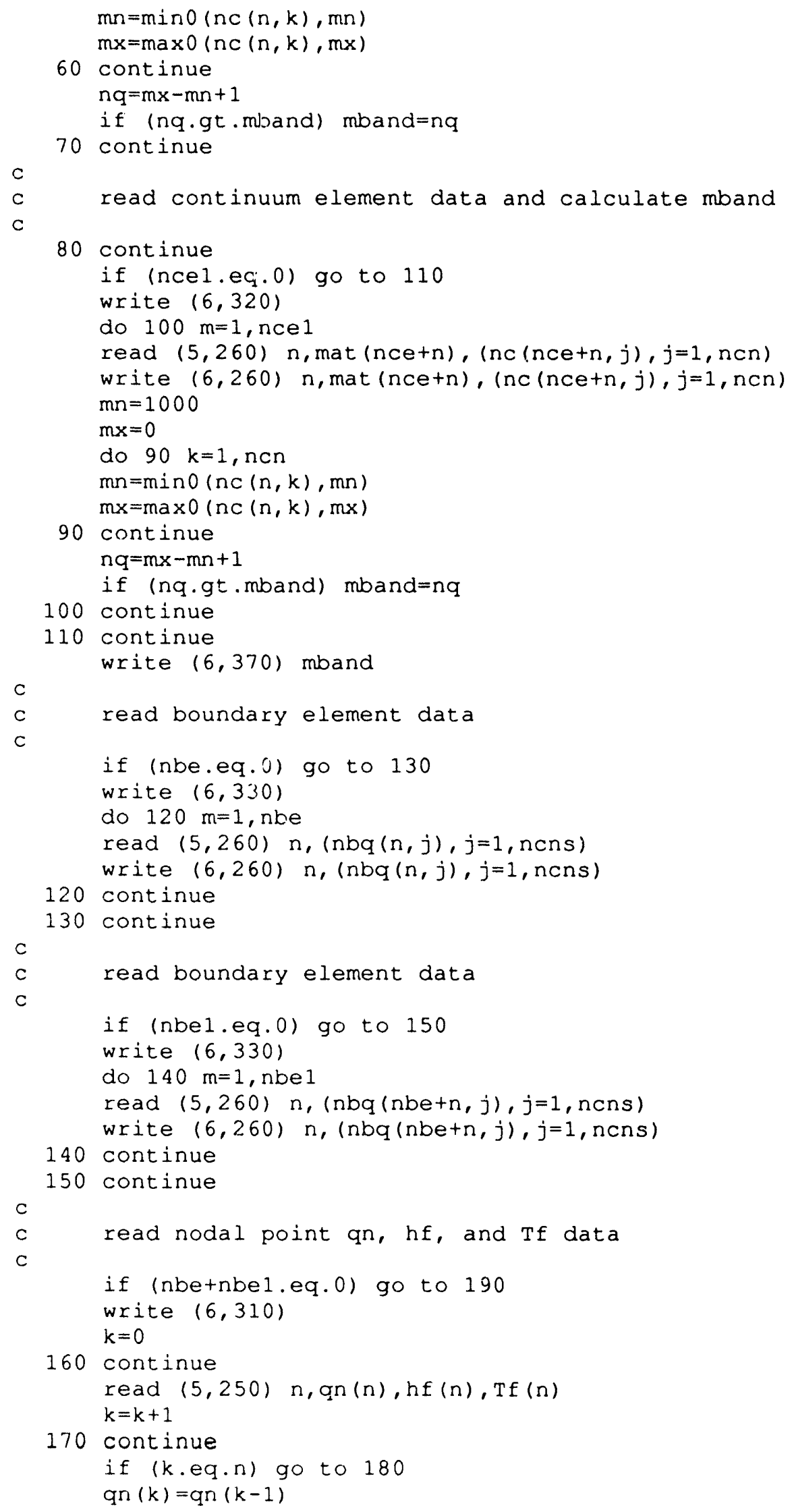




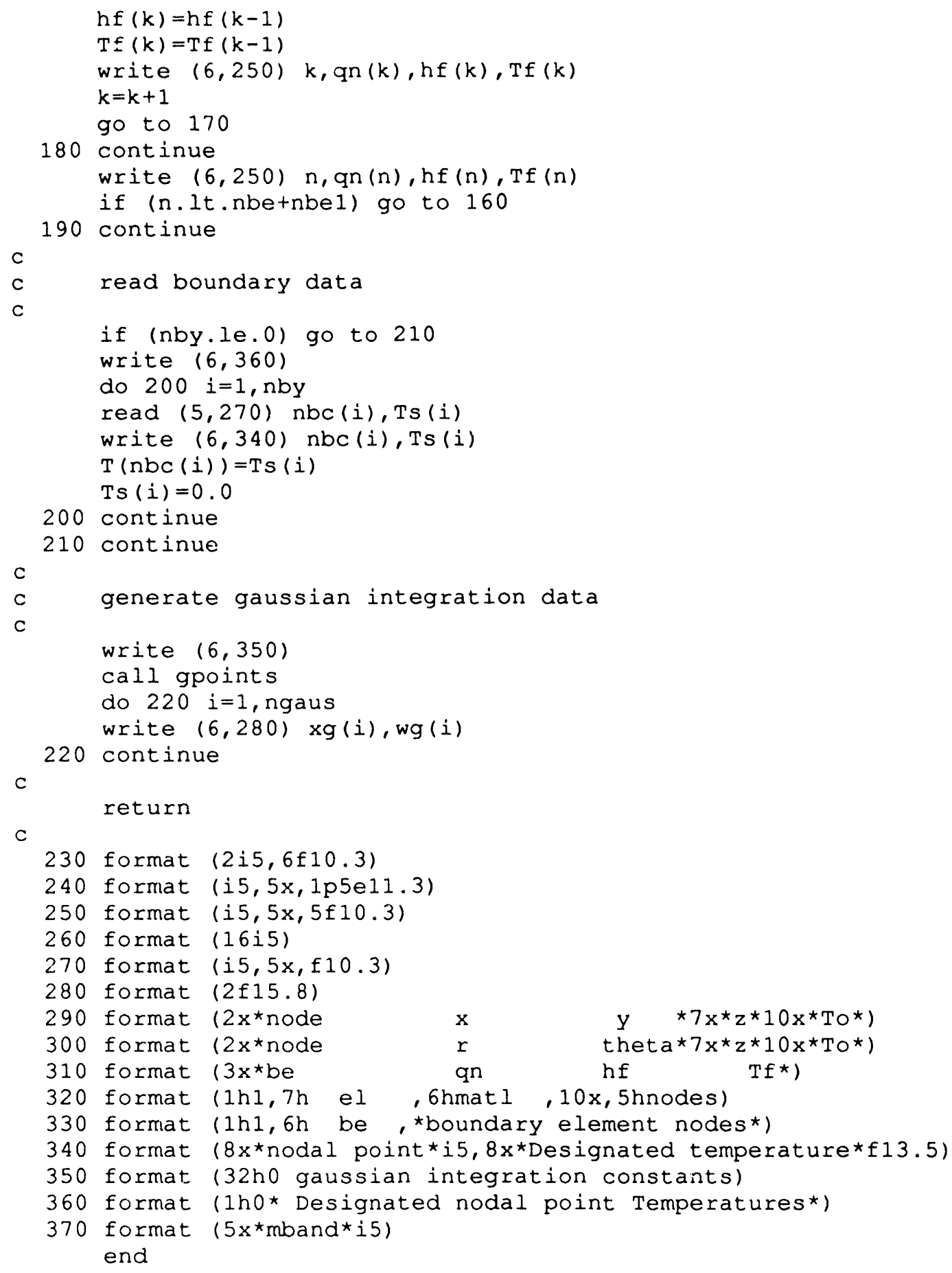




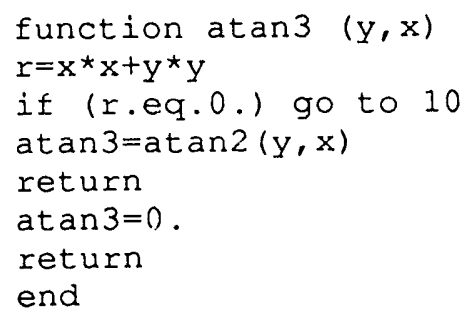




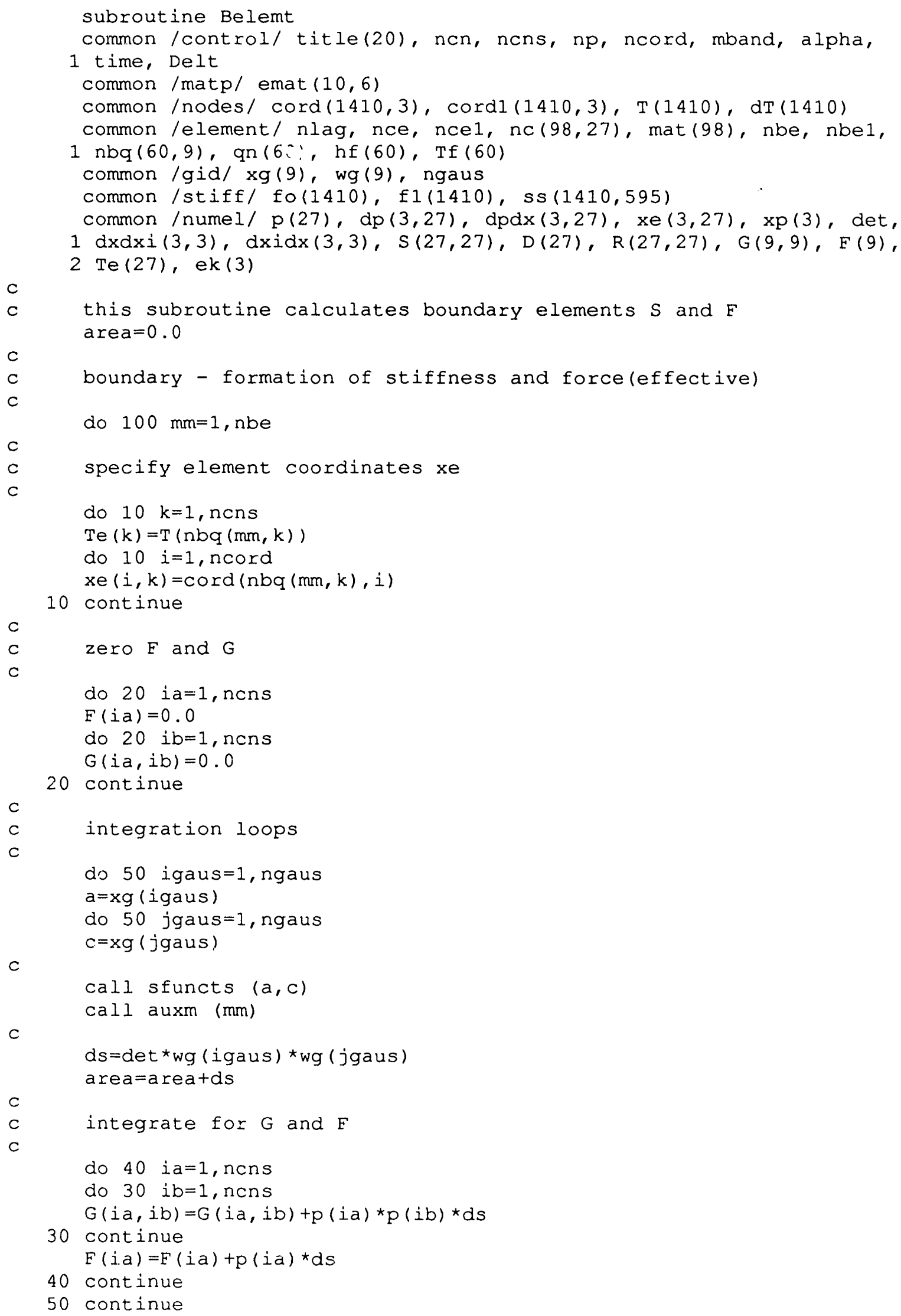




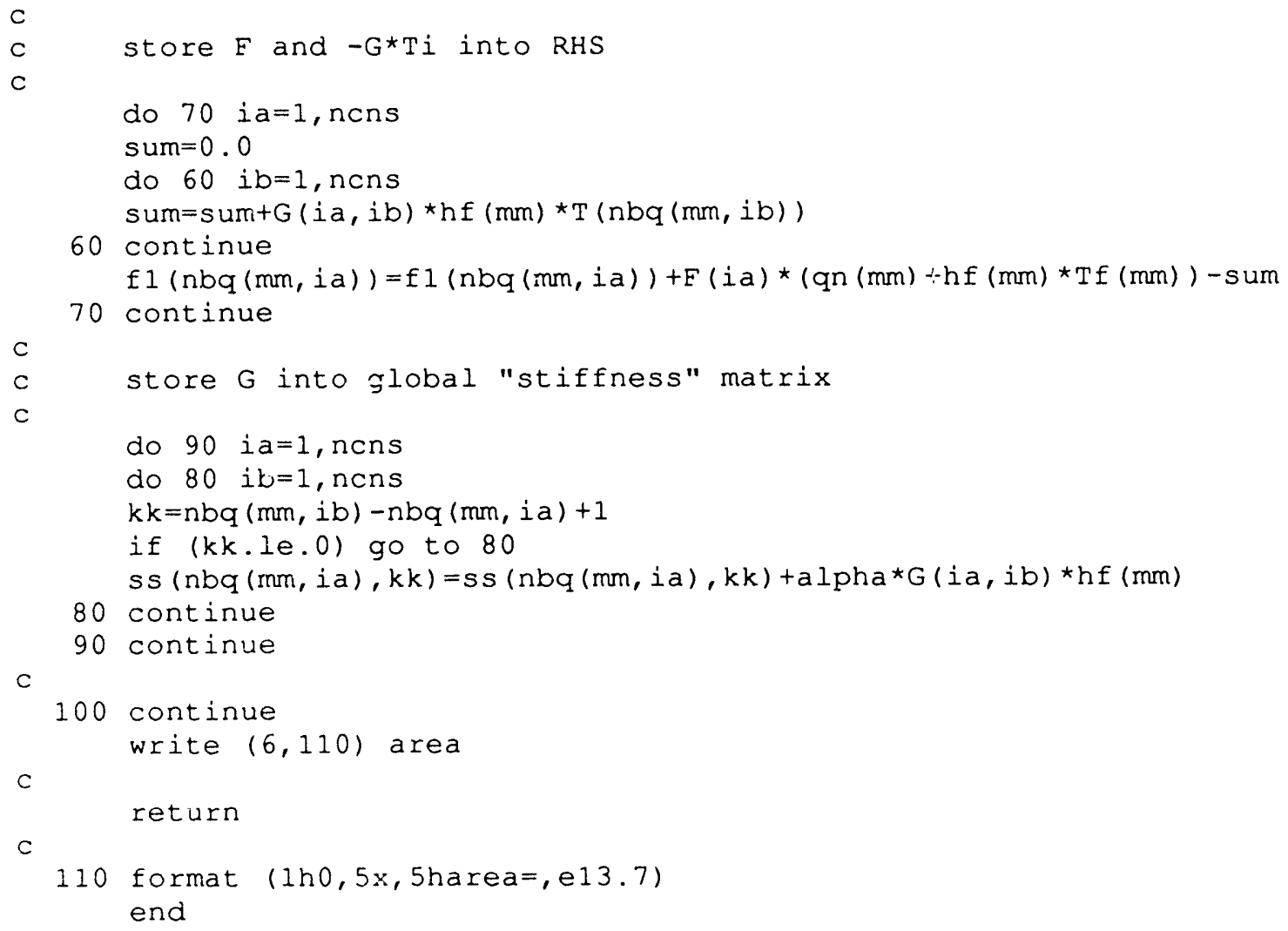




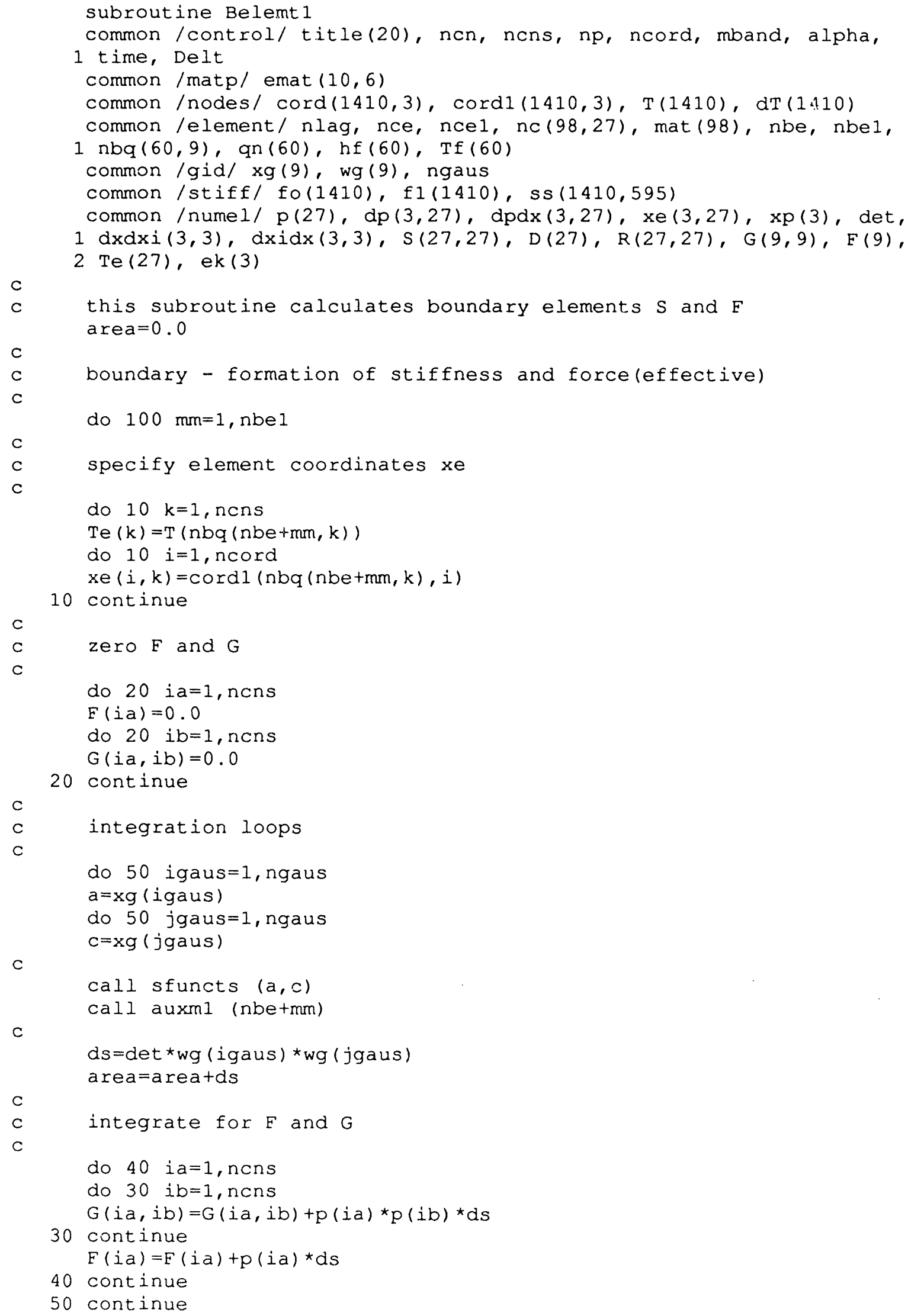


C

c store $F$ and $-G * T i$ into RHS

C

do 70 ia $=1$, ncns

sum $=0.0$

do $60 \mathrm{ib}=1$, ncns

sum $=\operatorname{sum}+G(i a, i b) \star h f(n b e+m m) * T(n b q(n b e+m m, i b))$

60 continue

$f 1(\mathrm{nbq}(\mathrm{nbe}+\mathrm{mm}, i \mathrm{a}))=f 1(\mathrm{nbq}(\mathrm{nbe}+m m, i a))+F(i a) *(\mathrm{~g} n(\mathrm{nbe}+\mathrm{mm})+\mathrm{h} f(\mathrm{nbe}+\mathrm{mm})$

$1 \star T f(n b e+m m))$-sum

c

70 continue

C

C

store G into global "stiffness" matrix

do 90 ia $=1$, ncns

do $80 \mathrm{ib}=1$, nons

$k k=n b q(m m, i b)-n b q(m m, i a)+1$

if $(k \mathrm{k} . \mathrm{le} .0)$ go to 80

$s s(n b q(n b e+m m, i a), k k)=s s(n b q(n b e+m m, i a), k k)+a l p h a \star G(i a, i b) \star h f(n b e$

$1+m m)$

80 continue

90 continue

c

100 continue

write $(6,110)$ area

C

return

C

110 format ( 1 ho $, 5 x, 5$ harea $=$, e13.7)

end 


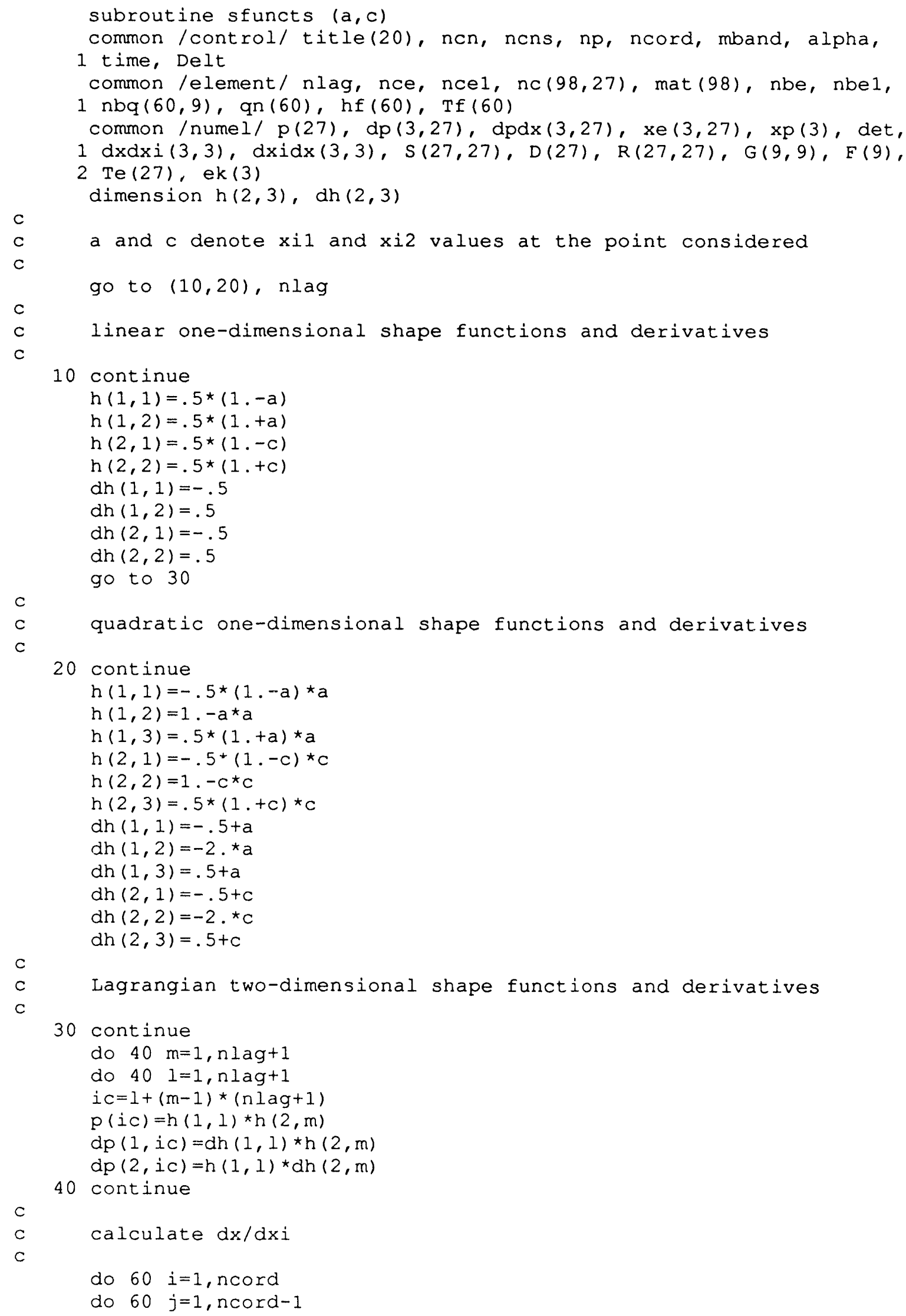


$d x d x i(i, j)=0$.

do $50 \mathrm{k}=1$, nons

$d x d x i(i, j)=d x d x i(i, j)+x e(i, k) \star d p(j, k)$

50 continue

60 continue

return

end 


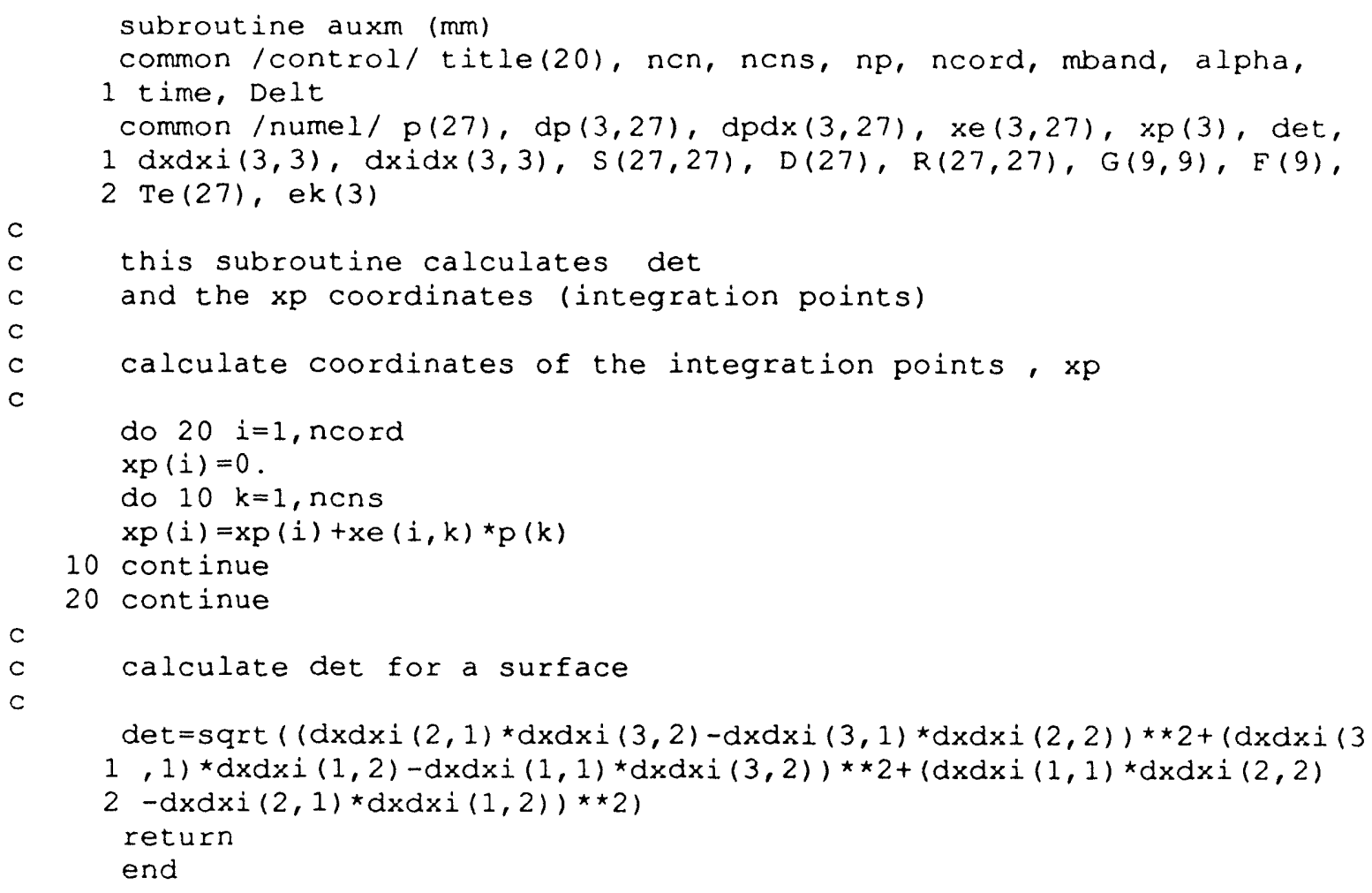




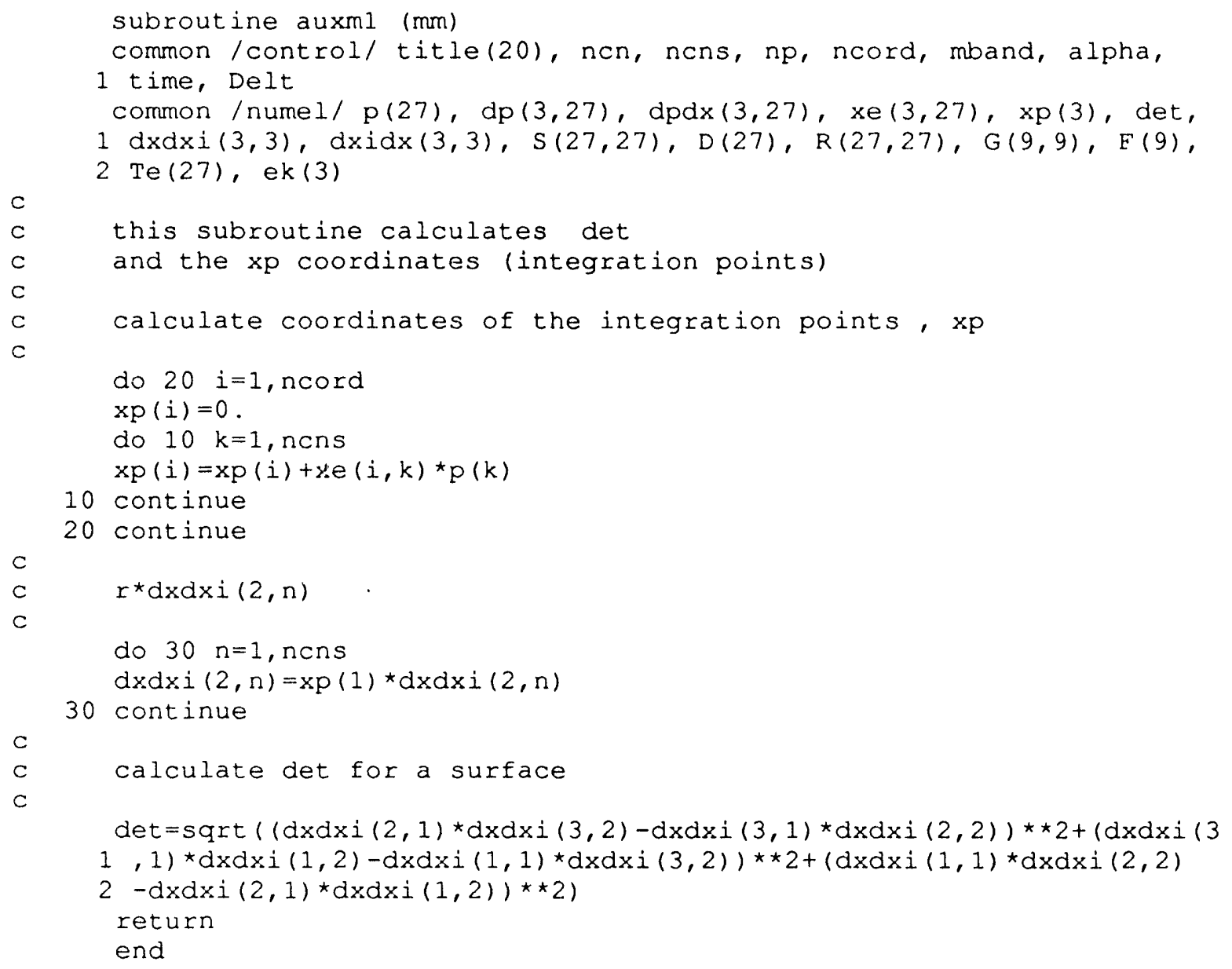




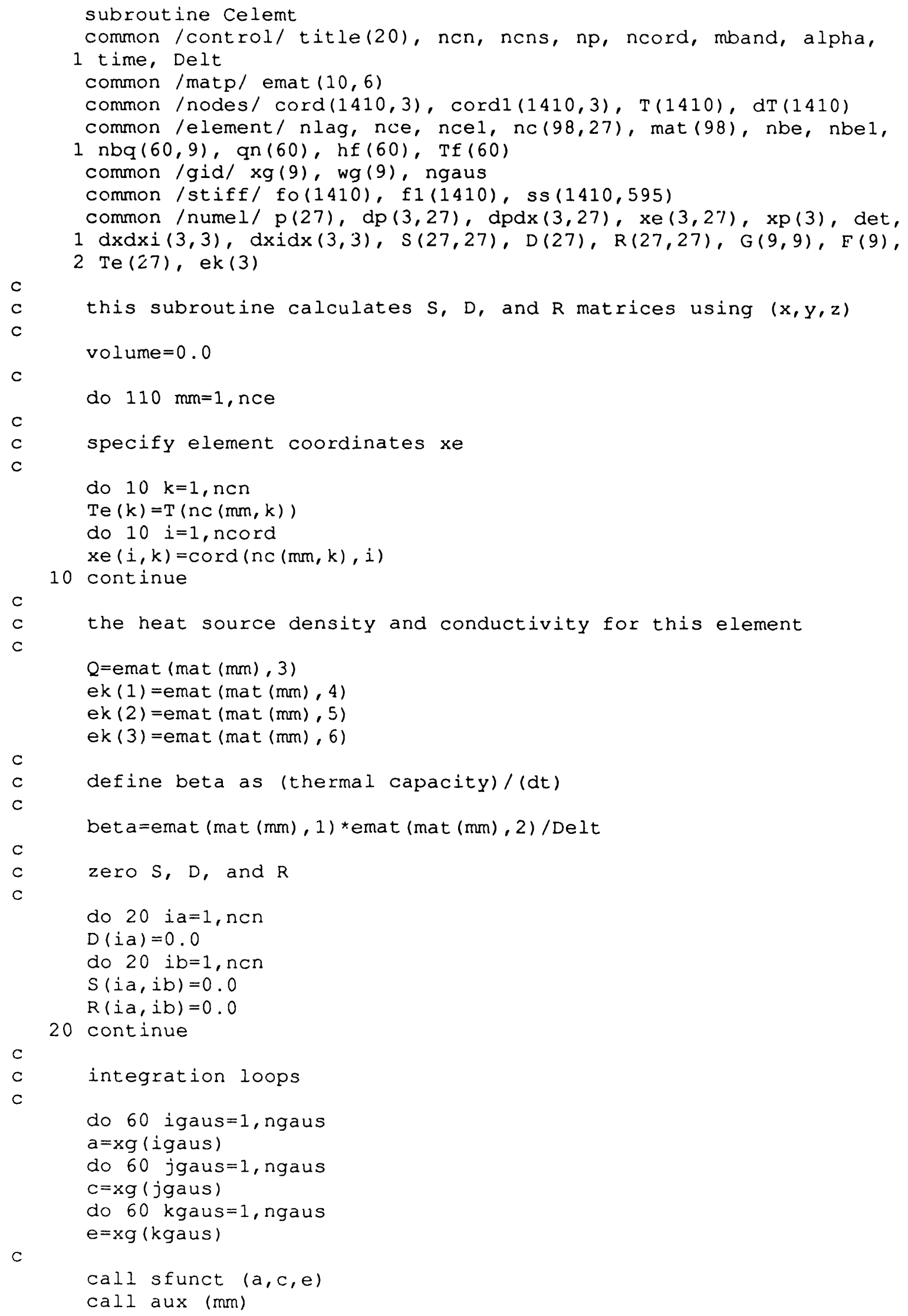


c

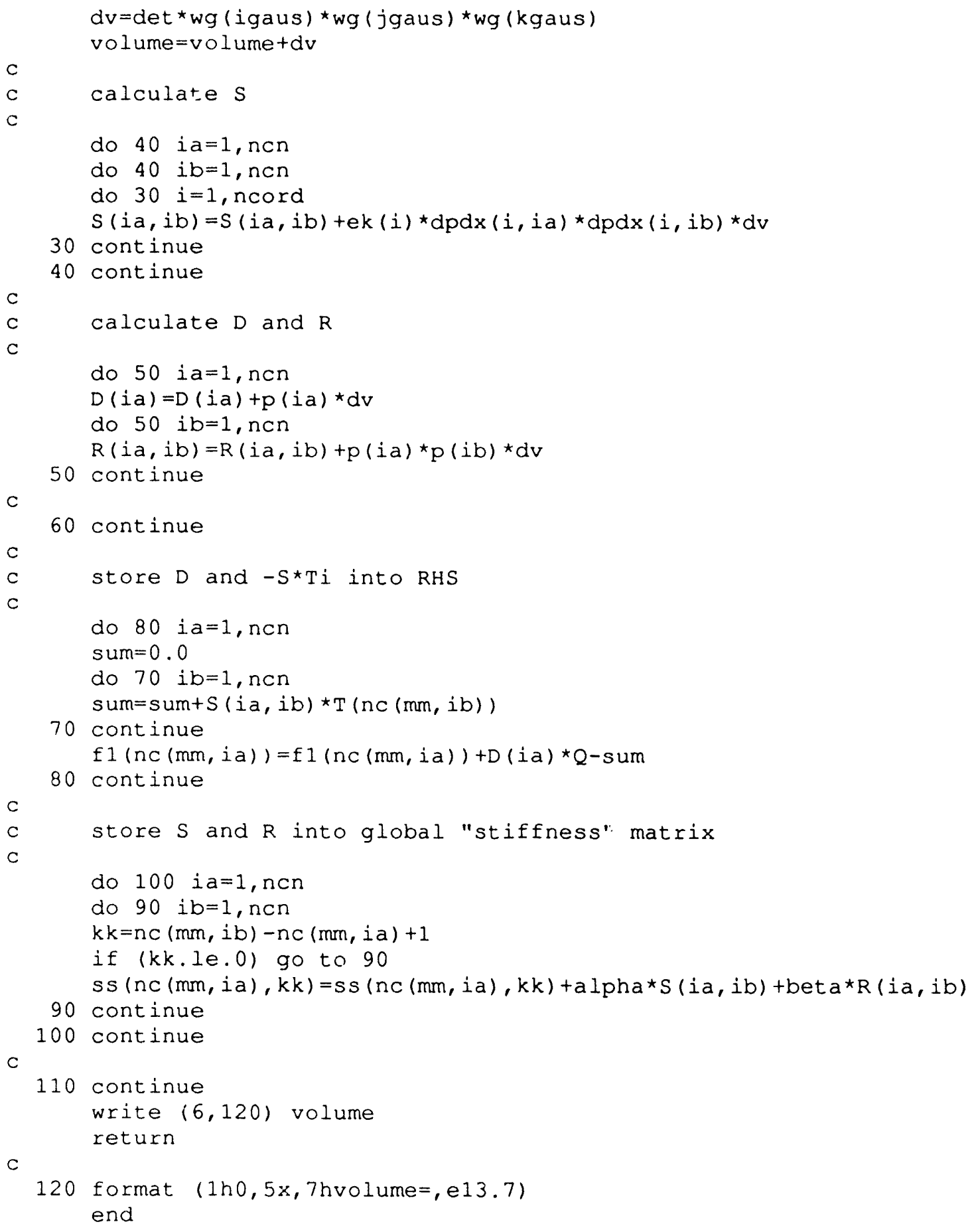


subroutine celemt 1

common /control/ title(20), ncn, nons, np, ncord, mband, alpha,

1 time, Delt

common /matp/ emat $(10,6)$

common /nodes/ cord $(1410,3), \operatorname{cord} 1(1410,3), \mathrm{T}(1410), \mathrm{dT}(1410)$

common /element/ nlag, nce, ncel, nc $(98,27)$, mat (98), nbe, nbel,

$1 \mathrm{nbq}(60,9), \mathrm{qn}(60), \mathrm{h} f(60), \operatorname{Tf}(60)$

common $/ \mathrm{gid} / \mathrm{xg}(9)$, wg(9), ngaus

common/stiff/ fo(1410), f1(1410), ss $(1410,595)$

common /numel/ $p(27), d p(3,27), d p d x(3,27), x e(3,27), x p(3), d e t$,

$1 \mathrm{dxdxi}(3,3), \mathrm{dxidx}(3,3), \mathrm{S}(27,27), \mathrm{D}(27), \mathrm{R}(27,27), \mathrm{G}(9,9), F(9)$,

$2 \mathrm{Te}(27), \mathrm{ek}(3)$

C

c

C

C

C

C

C

c

C

C

C

c

c

$\mathrm{C}$

C

c

this subroutine calculates $S, D$, and $R$ matrices using $(r$, theta, $z$ )

volume $=0.0$

do $120 \mathrm{~mm}=1$, nce 1

specify element coordinates xe

do $10 k=1$, ncn

$\mathrm{Te}(k)=\mathrm{T}(\mathrm{nc}(\mathrm{nce}+\mathrm{mm}, \mathrm{k}))$

do $10 i=1$, ncord

xe $(i, k)=\operatorname{cord} 1(n c(n c e+m m, k), i)$

10 continue

the heat source density and conductivity for this element

$Q=\operatorname{emat}(\operatorname{mat}($ nce $+\mathrm{mm}), 3)$

ek $(1)=\operatorname{emat}(\operatorname{mat}($ nce $+\mathrm{mm}), 4)$

ek $(2)=$ emat $($ mat $($ nce + mm $), 5)$

ek $(3)=e m a t(\operatorname{mat}($ nce + mm $), 6)$

define beta as (thermal capacity)/(dt)

bet $a=e m a t(\operatorname{mat}($ nce $+m m), 1) * \operatorname{emat}(\operatorname{mat}($ nce $+m m), 2) /$ Delt

zero $S, D$, and $R$

do 20 ia $=1$, ncn

$D(i a)=0.0$

do $20 i b=1, n c n$

$S(i a, i b)=0.0$

$R(i a, i b)=0.0$

20 continue

integration loops

do 70 igaus $=1$, ngaus

$a=x g$ (igaus)

do 70 jgaus $=1$, ngaus

$\mathrm{C}=\mathrm{xg}$ (jgaus)

do 70 kgaus $=1$, ngaus

$e=x g($ kgaus $)$

call sfunct $(a, c, e)$

call aux (ncetmm) 


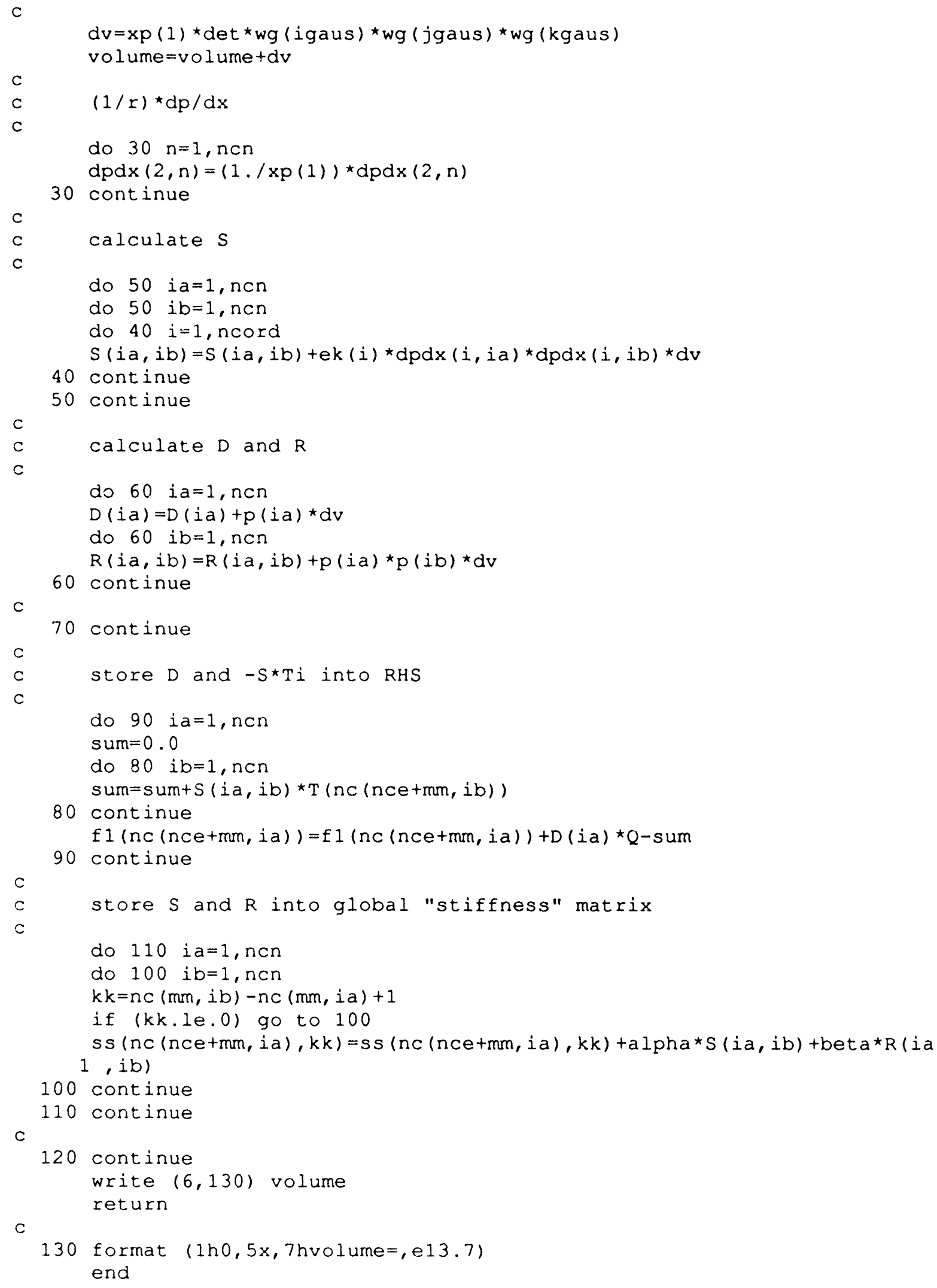


C

subroutine sfunct $(a, c, e)$

common /element/ nlag, nce, ncel, nc(98,27), mat(98), nbe, nbel,

$1 \mathrm{nbq}(60,9), \mathrm{qn}(60), \mathrm{hf}(60), \mathrm{Tf}(60)$

common /numel/ $p(27), d p(3,27), \operatorname{dpdx}(3,27), x e(3,27), x p(3), \operatorname{det}$,

$1 \mathrm{dxdxi}(3,3), \mathrm{dxidx}(3,3), \mathrm{S}(27,27), \mathrm{D}(27), \mathrm{R}(27,27), \mathrm{G}(9,9), E(9)$,

2 Te (27), ek(3)

dimension $h(3,3), \operatorname{dh}(3,3)$

$\mathrm{C}$

C

$a, c$, and $e$ denote $x i 1, x i 2$, and $x i 3$ values at the point considered go to $(10,20)$, nlag

C

C

C

10 continue

$h(1,1)=.5 *(1 .-a)$

$h(1,2)=.5 *(1 .+a)$

$h(2,1)=.5 *(1,-c)$

$h(2,2)=.5 *(1 .+c)$

$h(3,1)=.5 *(1 .-e)$

$h(3,2)=.5 *(1 .+e)$

dh $(1,1)=-.5$

$\operatorname{dh}(1,2)=.5$

$\mathrm{dh}(2,1)=-.5$

$\operatorname{dh}(2,2)=.5$

$\operatorname{dh}(3,1)=-.5$

$\operatorname{dh}(3,2)=.5$

go to 30

C

quadratic one-dimensional shape functions and derivatives

20 continue

$h(1,1)=-.5 \star(1 .-a) \star a$

$h(1,2)=1 .-a^{\star} a$

$h(1,3)=.5^{\star}(1 .+a) \star a$

$h(2,1)=-.5 \star(1,-c) \star c$

$h(2,2)=1 .-c^{\star} c$

$h(2,3)=.5 *(1 .+c) \star c$

$h(3,1)=-.5 \star(1 .-e) \star e$

$h(3,2)=1 .-e^{\star} e$

$h(3,3)=.5^{\star}(1 .+e) \star e$

$\operatorname{dh}(1,1)=-.5+a$

$\operatorname{dh}(1,2)=-2 . \star a$

$\operatorname{dh}(1,3)=.5+a$

$\operatorname{dh}(2,1)=-.5+c$

$\mathrm{dh}(2,2)=-2 .{ }^{\star} \mathrm{C}$

$\mathrm{dh}(2,3)=.5+\mathrm{c}$

dh $(3,1)=-.5+e$

$\mathrm{dh}(3,2)=-2$. ${ }^{\star} \mathrm{e}$

$\operatorname{dh}(3,3)=.5+e$

c

c

30 continue

do $40 n=1, n l a r+1$

do $40 \mathrm{~m}=1, \mathrm{nlag}+1$

do $401=1$, nlagt 1 
$i \mathrm{C}=1+(m-1) *(n \operatorname{lag}+1)+(n-1) *(n \operatorname{lag}+1) *(n \operatorname{lag}+1)$

$p(i c)=h(1,1) * h(2, m) * h(3, n)$

$\mathrm{dp}(1, i c)=d h(1,1) \star \mathrm{h}(2, \mathrm{~m}) \star_{h}(3, \mathrm{n})$

$\mathrm{dp}(2, i c)=h(1,1) \star \mathrm{dh}(2, \mathrm{~m}) \star \mathrm{h}(3, \mathrm{n})$

$d p(3, i c)=h(1,1) \star h(2, m) \star d h(3, n)$

40 continue

return

end 
C 
do $80 j=1$, ncord

$\operatorname{dpdx}(i, n)=\operatorname{dpdx}(i, n)+d p(j, n) \star d x i d x(j, i)$

80 continue

90 continue

return

C

100 format ( $1 \mathrm{~h} 0,38 \mathrm{~h}$ negative det stopped at, element no =, i3)

110 format (1h0,23hzero determinent el no, i3)

end 
subroutine gpoints

common /gid/ xg(9), wg(9), ngaus

this subroutine calculates Gauss points for integration

go to $(10,20,30,40,50,60,70,80,90)$, ngaus

$10 \mathrm{xg}(1)=0$.

$\operatorname{wg}(1)=2$

return

$20 \mathrm{xg}(1)=-0.577350269189626$

$\mathrm{wg}(1)=1$.

go to 100

$30 \mathrm{xg}(1)=-0.774596669241483$

$\mathrm{xg}(2)=0$.

$\mathrm{wg}(1)=0.55555555555556$

$w g(2)=0.888888888888889$

go to 100

$40 \mathrm{xg}(1)=-0.861136311594053$

$x g(2)=-0.339981043584856$

$\operatorname{wg}(1)=0.347854845137454$

$\operatorname{wg}(2)=0.652145154862546$

go to 100

$50 \mathrm{xg}(1)=-0.906179845938664$

$x g(2)=-0.538469310105683$

$\mathrm{xg}(3)=0$.

$w g(1)=0.236926885056189$

$w g(2)=0.478628670499366$

$w g(3)=0.568888888888889$

go to 100

$60 \mathrm{xg}(1)=-0.932469354203152$

$x g(2)=-0.661209386466265$

$\mathrm{xg}(3)=-0.238619186083197$

$w g(1)=0.171324492379170$

$\operatorname{wg}(2)=0.360761573048139$

$w g(3)=0.467913934572691$

go to 100

$70 \mathrm{xg}(1)=-0.949107912342759$

$x g(2)=-0.741531185599394$

$x g(3)=-0.405845151377397$

$x g(4)=0$.

$w g(1)=0.129484966168870$

$w g(2)=0.279705391489277$

$w g(3)=0.381830050505119$

$\operatorname{wg}(4)=0.417959183673469$

go to 100

$80 \mathrm{xg}(1)=-0.960289856497536$ $\mathrm{xg}(2)=-0.796666477413627$ $x g(3)=-0.525532409916329$

$x g(4)=-0.183434642495650$

$w g(1)=0.101228536290376$

$w g(2)=0.222381034453374$

$w g(3)=0.313706645877887$

$w g(4)=0.362683783378362$

go to 100

$90 \mathrm{xg}(1)=-0.968160239507626$

$x g(2)=-0.836031107326636$

$x g(3)=-0.613371432700590$

$x g(4)=-0.324253423403809$ 
$\mathrm{xg}(5)=0$.

wg $(1)=0.081274388361574$

$w g(2)=0.180648160694857$

$\operatorname{wg}(3)=0.260610696402935$

$w g(4)=0.312347077040003$

$w g(5)=0.330239355001260$

$100 \mathrm{n}=$ ngaus $/ 2$

do $110 \quad j=1, n$

$i=$ ngaus $+1-j$

$x g(i)=-x g(j)$

$110 \mathrm{wg}(i)=w g(j)$

return

end 


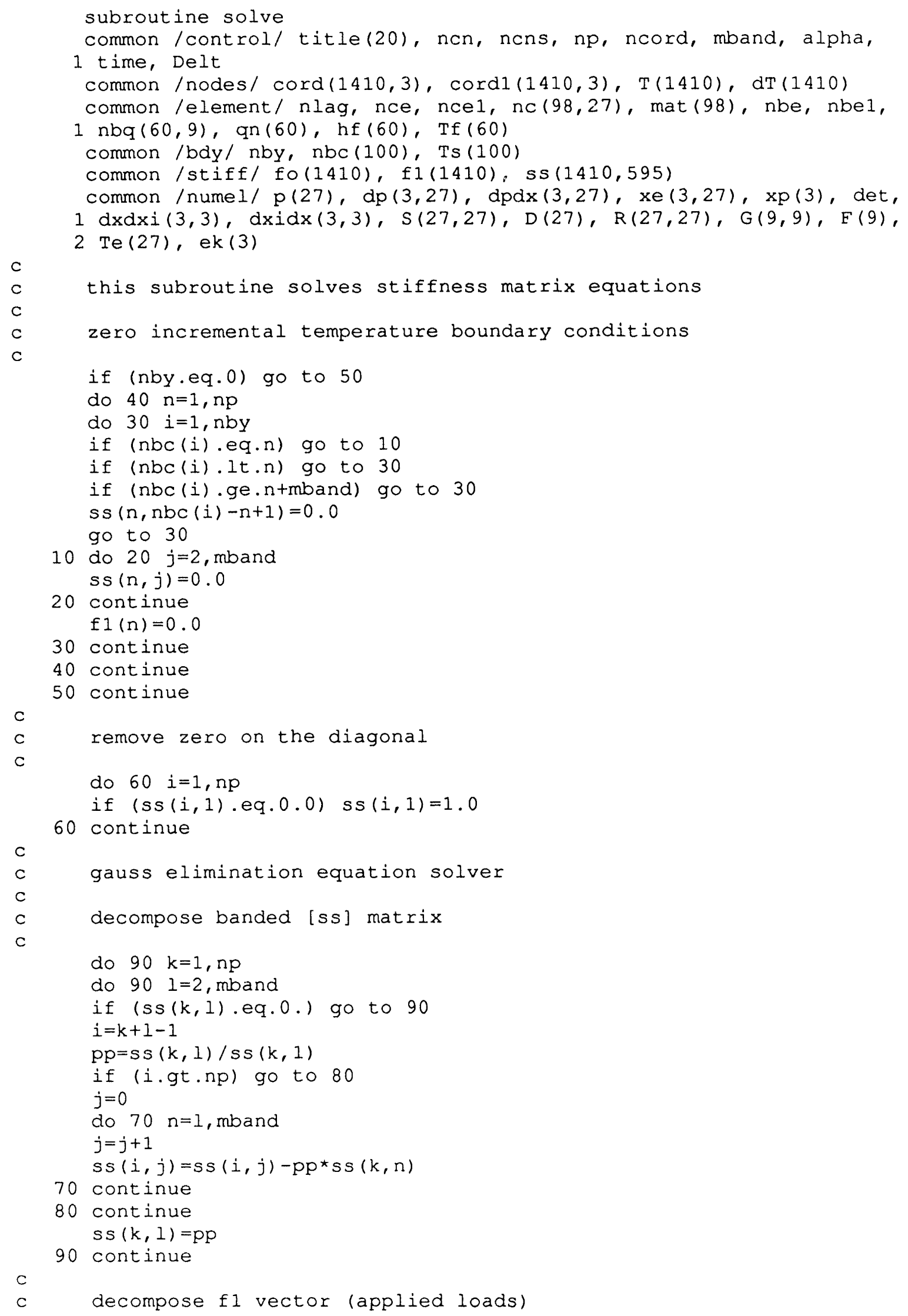


c

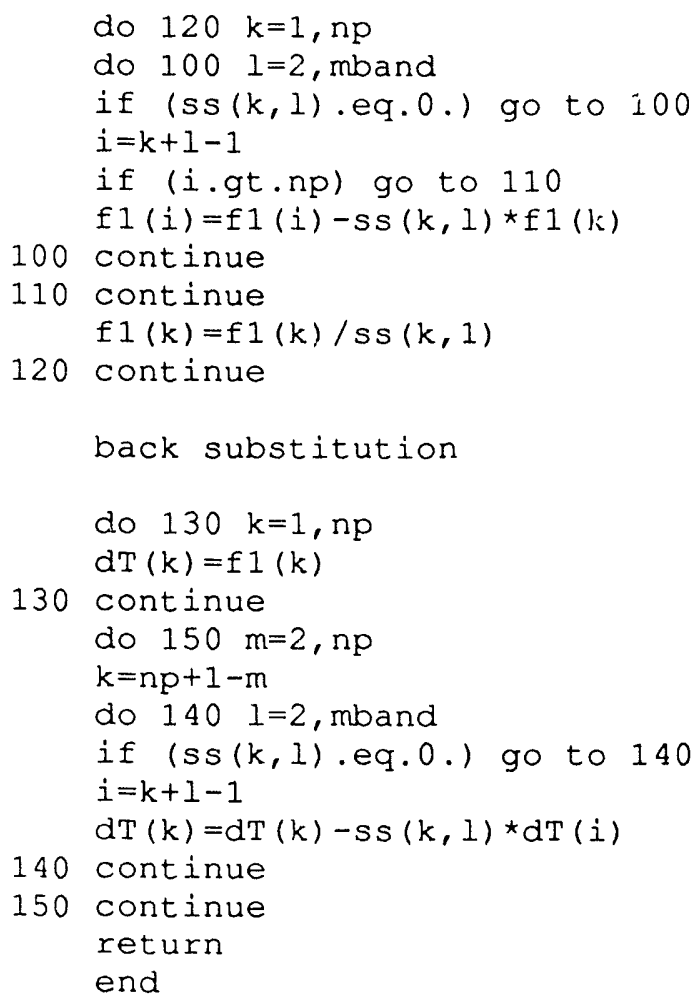




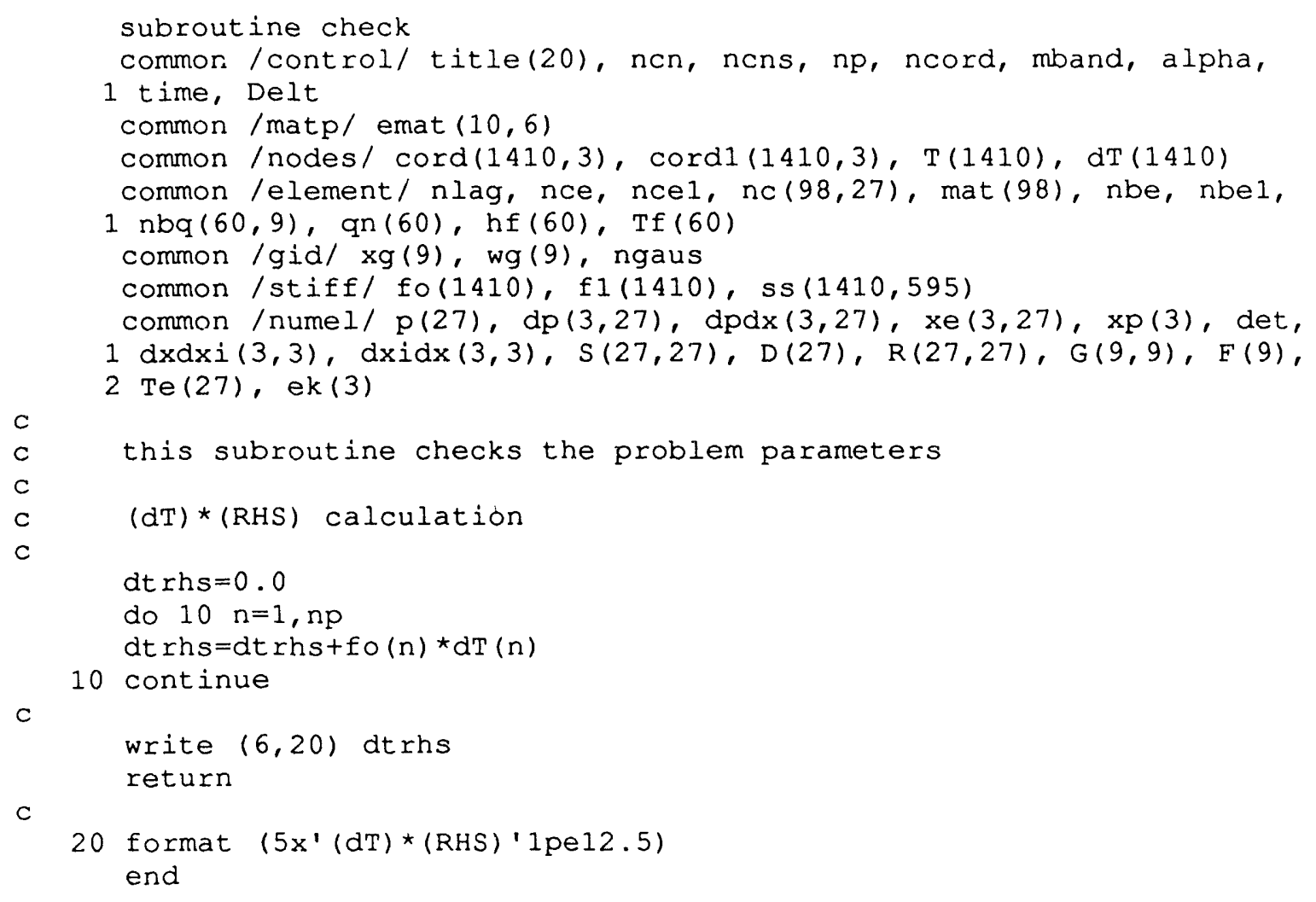



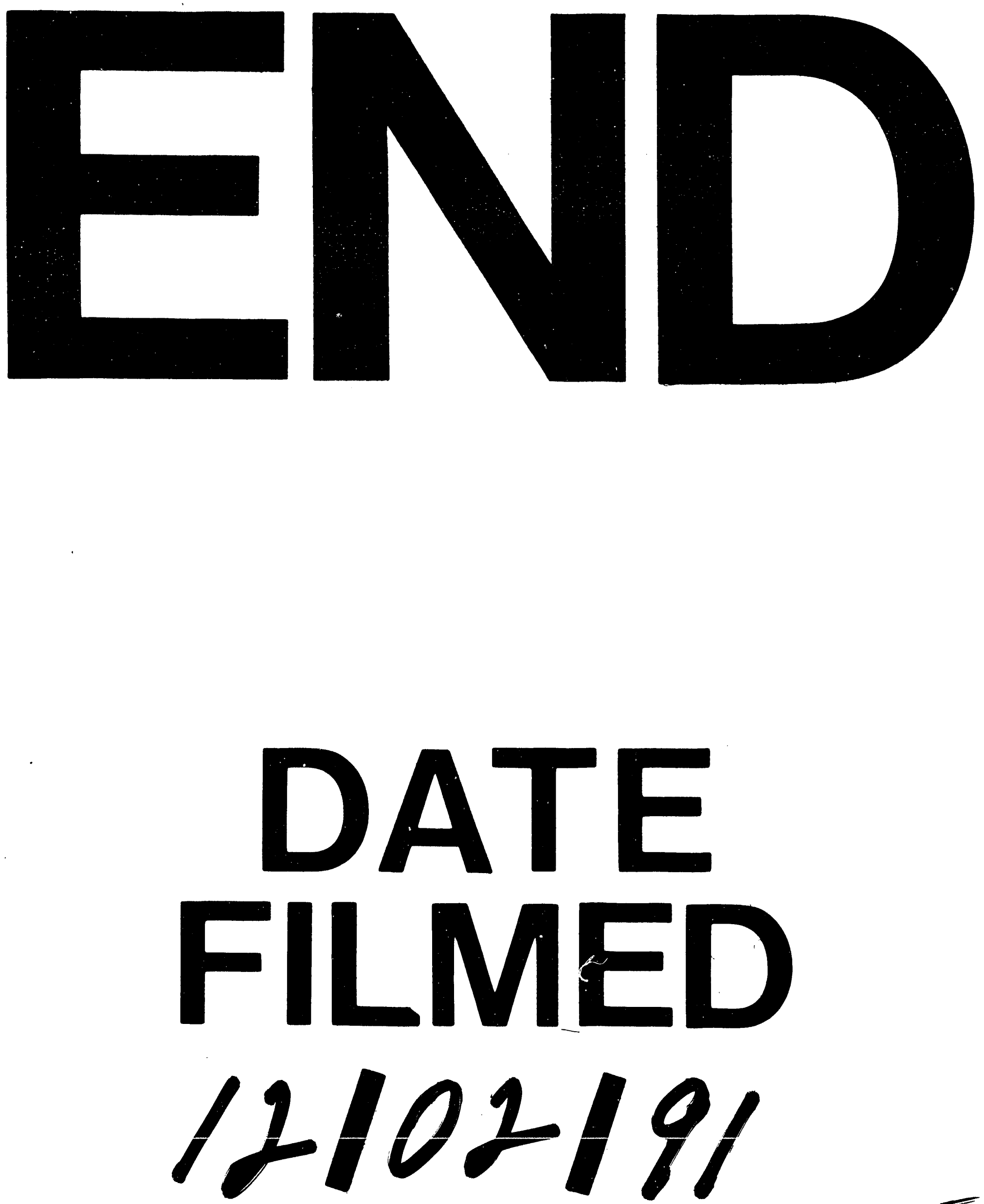

$I_{1}$ 
